\title{
Cell membrane engineering with synthetic materials: applications in cell spheroids, cellular glues and microtissue formation
}

\author{
Adérito J. R. Amaral, George Pasparakis* \\ UCL School of Pharmacy, University College London, 29-39 Brunswick Square, London \\ WC1N 1AX, U.K. \\ *Corresponding author \\ E-mail: g.pasparakis@ucl.ac.uk \\ Tel.: +44 2077535816
}

\begin{abstract}
Biologically inspired materials with tunable bio- and physicochemical properties provide an essential framework to actively control and support cellular behavior. Cell membrane remodeling approaches benefit from the advances in polymer science and bioconjugation methods, which allow for the installation of un-/natural molecules and particles on the cells' surface. Synthetically remodeled cells have superior properties and are under intense investigation in various therapeutic scenarios as cell delivery systems, bio-sensing platforms, injectable biomaterials and bioinks for 3D bioprinting applications. In this review article, recent advances in the field of cell surface remodeling via bio-chemical means and the potential biomedical applications of these emerging cell hybrids are discussed.
\end{abstract}

Keywords: Cell membrane engineering, cell aggregation, spheroids, 3D cell culture, cellular glues

\section{Statement of Significance}

Recent advances in bioconjugation methods, controlled/living polymerizations, microfabrication techniques and 3D printing technologies have enabled researchers to probe specific cellular functions and cues for therapeutic and research purposes through the formation of cell spheroids and polymer-cell chimeras. This review article highlights recent non-genetic cell membrane engineering strategies towards the 
fabrication of cellular ensembles and microtissues with interest in $3 \mathrm{D}$ in vitro modelling, cell therapeutics and tissue engineering. From a wider perspective, these approaches may provide a roadmap for future advances in cell therapies which will expedite the clinical use of cells, improving the quality and accessibility of disease treatments.

\section{Introduction}

With the advent of translational medicine, cell-based therapies have come to light as potential methods to deliver healthy cells to injured tissues in order to restore or enhance their function and ultimately treat medical conditions [1, 2]. The use of live cells as therapeutic entities established a new pillar in the biomedical field exerted by their intrinsic ability to sense the surroundings and adapt in accord to their microenvironment by exhibiting regulable behavior, leading to their natural integration with the host organism with potentially minimal side-effects $[2,3]$.

Cell therapeutics constitutes a fast evolving field in the medical sciences as an increasing number of synthetic procedures to intervene to biological functions have been reported, yet few have propelled their translation into the clinical setting. Recently, chimeric antigen receptor (CAR) T-cells therapies were approved by the U.S. Food and Drug Administration (FDA) for the treatment of specific leukemia and lymphomas [46]. Cellular engineering through genetic manipulation has been exploited to modulate the expression of specific surface receptors to improve the in vivo function of the cells, although these techniques are still associated with a number of significant drawbacks. One main reason is the unsatisfactory safety and efficacy guarantees, and the lack of control to promote the desirable cell phenotype. Other major hurdles facing the translation of cell therapies from the lab to the clinic include the low survival, poor tissue/organ specificity and the difficulty to recruit and attach a sufficient number of cells at the site of interest $[7,8]$.

In this context, biomaterials, in the form of polymer fillers, microcapsules or hydrogels, can act as synthetic analogs of the extracellular matrix (ECM) in order to provide an appropriate microenvironment for the cells to support their adhesion and retention and to promote their specific action, be it new tissue formation, protein/biomolecules secretion, or enzymatic activity [9-12]. Although various materials have been used as cell encapsulants and matrices for cell proliferation, toxicity and 
immunogenicity may hamper the full exploitation of this classic tissue engineering approach in the clinic [13-15]. A possible solution to this problem is the minimization of the bulk volume of the biomaterial used relative to the number of cells that are to be encapsulated. Ultimately, biomaterials that interact only at the cell membrane interface could constitute a realistic approach that mimics aspects of the ECM in order to mitigate toxicity, biocompatibility and often non-degradability problems.

Hence, the ability to engineer the cell membrane with synthetic materials at the nano/microscale to impart non-native properties to cells has emerged as a versatile tool to enhance the therapeutic potency of cells by mimicking their intrinsic hierarchical assembling properties which are naturally encountered in living organisms [16].

\section{The cell membrane}

The cell membrane and the ECM together constitute the most important functional dipole that regulates biological responses at the tissue and organ levels. The ECM is mainly composed of proteins, polysaccharides and glycosaminoglycans, it surrounds the cells to serve as a natural structural support, and provides biochemical and biophysical cues to regulate cellular processes and tissue functions, such as signaling, differentiation, migration, adhesion and repair [17]. Therefore, the understanding of cell-ECM dynamics is essential for the development of new ECM mimicking biomaterials for therapeutic purposes.

The cell membrane is a complex, heterogeneous and dynamic biological structure comprising different types of lipids, proteins and carbohydrates, which outlines the cell border and mediates extracellular communications [18]. The lipid bilayer, constituted mostly by cholesterol and phospholipids, acts as a selective physical barrier to the (bio-) chemical environment, osmotic pressure gradients and mechanical stress [19]. Membrane-associated carbohydrates may be bound either to lipids or proteins on the outer surface of the cell forming glycolipids or glycoproteins, respectively, which comprise the glycocalyx (or cell coat) [20]. These biomolecules play a central role in biorecognition, cell-cell and cell-ECM interactions, selective adhesion, enzymatic activity, molecular uptake and mass transport; they can activate intracellular signaling pathways that control fundamental functions such as signal transduction and gene expression, cell division, migration and differentiation [21]. Indeed, the plasma membrane can serve as an excellent chemical substrate for 
biomaterials design, however, its dynamic fluidity nature and heterogeneity constitutes a challenge for cell surface modification since its components are continuously internalized, degraded and replaced [22].

Given that several recently published articles focus on the modification of the cell surface via (bio-) chemical means, there is an increasing need to comprehensively overview the emerging field of material-mediated cell aggregation for biomedicine, the principal strategies to remodel the membrane of living cells to programme the construction of cellular assemblies for tissue engineering, cell delivery and as in vitro microtissue models, and to describe the therapeutic potential, challenges and future perspectives in this prominent field. Contemporary biofabrication methods, namely 3D bioprinting methodologies to form and deposit cell spheroids and to direct tissue microassembly, are discussed.

\section{Non-genetic cell membrane engineering approaches}

During the last three decades, cell membrane engineering has provided an invaluable toolbox to regulate the molecular and biochemical composition of the cellular interface and investigate the processes governed by the plasma membrane components, such as signal transduction, endocytosis, adhesion, migration and cell-cell interactions [20, 23, 24]. These approaches have expanded beyond fundamental research into more practical applications, including drug delivery, cell encapsulation or biosensing/recognition, as well as to study cellular aggregation processes and formation of tissue-like organized structures [25-28]. For this reason, it is important to understand the bio-interface and the different design aspects that must be taken into consideration in cell membrane interacting materials: i) the maintenance of the cell viability which requires strategies or materials compatible with the physiological conditions; ii) stability of the exogenous materials at the surface since these strategies can be transient due to membrane turnover, mitosis or degradation, which can lead to rapid internalization; iii) density and distribution adjustment of the active sites on the surface, and iv) the mechanism of immobilization of macromolecules, which can impact the robustness, interactions and universality of the system [29, 30].

In this perspective, several strategies have been developed to selectively decorate the cell surface with exogenous moieties, such as nucleic acids, peptides, antibodies, nanoparticles (NPs) and polymers, to enhance the therapeutic potential and 
longevity of the transplanted cells, without adversely affecting their viability and processes caused by the possible hindrance of nutrients/ions transportation, inhibition of the cell cycle or direct effect of the materials on the membrane [30, 31].

Covalent and non-covalent bonding strategies have been used to directly modify the cell surface which include the metabolic incorporation of bioorthogonal groups onto the cell membrane, the versatile chemical conjugation with specific functional groups (i.e. primary amines, thiols and diols) naturally present on cell membrane glycoproteins, the exploitation of electrostatic interactions between cationic polymers and the anionic membrane lipids, or the insertion of amphiphilic materials into the lipid bilayer via hydrophobic interactions.

$\mathrm{N}$-hydroxysuccinimide (NHS) ester derivatives have been extensively studied for protein crosslinking and labelling through covalent coupling with primary amines $[32,33]$. These amino groups exist at the N-terminus of each polypeptide chain and side-chain of lysine amino acid residues, which make them accessible to conjugation with NHS reagents in pH-dependent way. NHS esters can undergo hydrolysis in aqueous media but aminolysis is preferred in the presence of amines [34]. For example, the Chaikof group showed that it was possible to covalently couple NHS-derived poly(ethylene glycol) (PEG) copolymers with thrombomodulin on the membrane of pancreatic islets to reduce the thrombogenic effect of their transplantation [35]. These synthetic polymers were excluded from the cell surface within 24 hours, without cytoplasmatic uptake, probably due to the hydrolysis of amide bonds by proteases [36]. Other studies explored the reaction of NHS-biotin derivatives with primary amines at the surface; Karp and co-workers immobilized sialyl Lewis X (SLeX) tetrasaccharides on mesenchymal stem cells (MSCs) through biotin-streptavidin bridges, which imparted a leukocyte-like rolling response on activated endothelium to increase the targeting efficiency, without any adverse effect on the cells phenotype and differentiation potential $[37,38]$.

Irvine et al. described the chemical conjugation of drug-loaded NPs, bearing a maleimide-functionalized phospholipid surface layer, with thiols present on the membrane of T-cells without affection key cellular functions [39]. It was shown that the prolonged retention of the particles on the cell surface (ca. 4 days) enabled sustained delivery of adjuvant drugs and continuous pseudoautocrine stimulation of transferred cells in vivo. Francis and colleagues directly installed DNA strands by coupling a NHSPEG-maleimide crosslinker with amino groups present on the membrane proteins 
(physiological $\mathrm{pH}$ ), followed by maleimide conjugation of thiolated DNA strands; the researchers reported the capture of red blood cells (RBCs), primary T-cells and myoblasts aiming for the incorporation of living cells into devices [40].

Alternatively, boronic acids have been used to reversibly bind polymers to glycoproteins present on the cell membranes. The dynamic covalent nature of this group allows for the selective attachment to cis-diols residues, such as sialic acid or galactose units, in a pH-dependent manner, with interest in insulin delivery, molecular sensing, cell capture/release and cell culture [41-44]. As an illustration, Hubbell and co-workers synthesized a poly(L-lysine)-graft-poly(ethylene glycol) (PLL-g-PEG) copolymer modified with phenylboronic acid (PBA), which could form covalent but reversible complexes with cis-diols of the oligosaccharides on the glycosylated surface of RBCs at physiological $\mathrm{pH}$, while the PEG domain would provide a molecular barrier to protein and cell adhesion owing to steric interaction of the polymer backbone, preventing the binding of antibodies in transplanted cells [45]. Jiang et al. grafted a PBA-based polymer from the surface of silicon nanowire arrays to selectively attach breast cancer cells by boronate ester bond formation with the (overexpressed) sialic acid residues on glycoproteins (Fig. 1a). At physiological pH, the addition of an excess of free glucose could trigger cells detachment, driven by the competitive binding, without affecting their viability [46].

Covalent remodeling of the cell membrane is virtually limited to the readily available functional groups; however, indirect immobilization methods that require additional steps to introduce non-native reactive groups have also been exploited. These processes, which involve the oxidation of sialic acid or galactose residues mediated by sodium periodate or galactose oxidase, respectively, as well as metabolic engineering, are employed to install aldehydes, ketones or azides on the cell surface [24, 47, 48]. Although pertinent, these approaches are occasionally complex and may perturb the cellular microenvironment.

In contrast to chemical approaches, physical methods are often transient in nature and may not sustain the materials in a mechanically demanding environment in the longer term, however, they can minimize the potential toxic effect exerted on the membrane biomolecules. Several groups have reported the encapsulation of cells for transplantation by anchoring amphiphilic materials on the outer leaflet of the membrane through hydrophobic interaction with the phospholipids [49-51]. In a similar method, lipid vesicles functionalized with chemoselective groups have been fused directly with 
the plasma membrane. For example, Karp et al. have shown that MSCs could be engineered to present SLeX on the membrane through lipid vesicles fusion to promote cell rolling on the endothelium and consequently improve cell homing and targeting (Fig. 1b) [52]. The short-term stability and accessibility of the biotinylated lipids $(<24$ hours) could be due to their internalization within the cells or escape from the surface into the external environment. Recently, Hsieh-Wilson and co-workers used an analogous approach to attach sulfated glycosaminoglycans on the membrane, which activated key intracellular signaling pathways and enhanced axonal growth [53].

Another strategy - layer-by-layer (LbL) assembly - involves the alternate deposition of oppositely charged polymers on the (negatively-charged) cell surface driven by multivalent electrostatic interactions [54, 55]. Chaikof and colleagues reported the encapsulation of pancreatic islets through electrostatic adsorption of PLL$g$-PEG copolymers to create films with tunable biological and physicochemical properties, which could act as immunoisolation barriers for cell transplantation and controlled release of therapeutic molecules [56].

From the previous studies, it is apparent that the nature of the anchoring molecule (or higher order entities, such as nanoparticles, vesicles, etc.) may determine the duration of the immobilization events before being depleted by the continuous lipid turnover of the cell membrane. Generally, small molecules and polymers anchored physically or chemically tend to persist for up to ca. 24 hours as they are uptaken by the rapid lipid-raft endocytosis pathway [57-59], whereas larger objects (e.g. nanoparticles or vesicles) $[39,60,61]$ have increased immobilization retention times for considerably longer timeframes as they are eventually uptaken by higher-energy uptake mechanisms such as clathrin/caveolae-mediated endocytosis. Nevertheless, membrane recycling can also return hydrophobic ligands to the surface, prolonging their lifetime during cell division $[62,63]$. 
a)
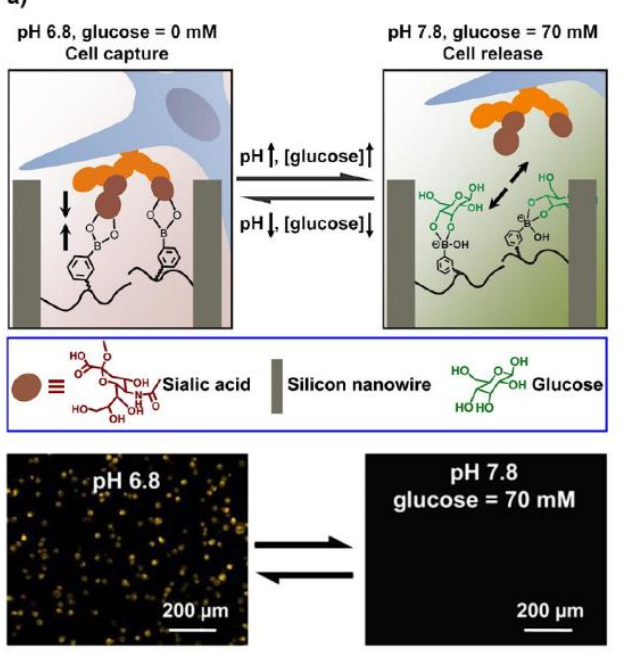

b)

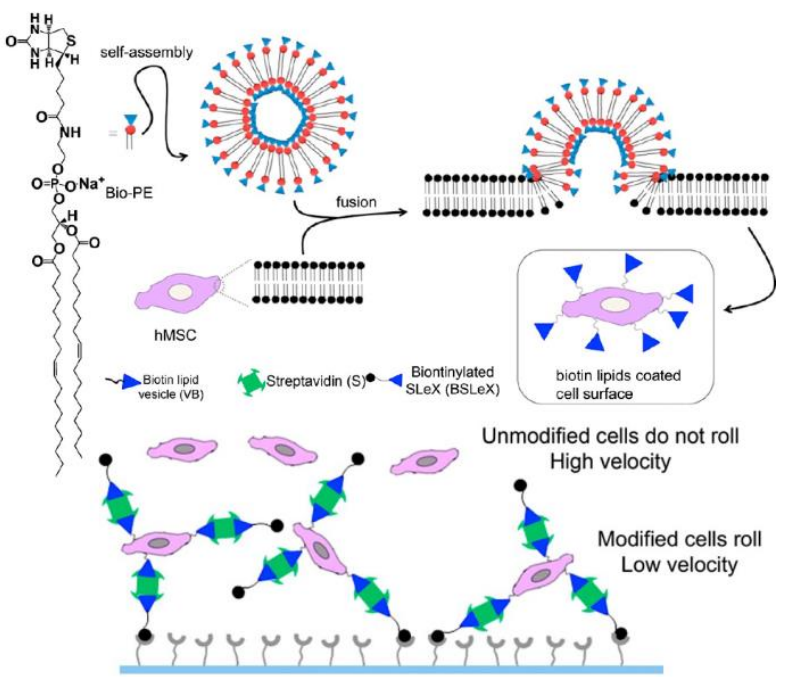

c)

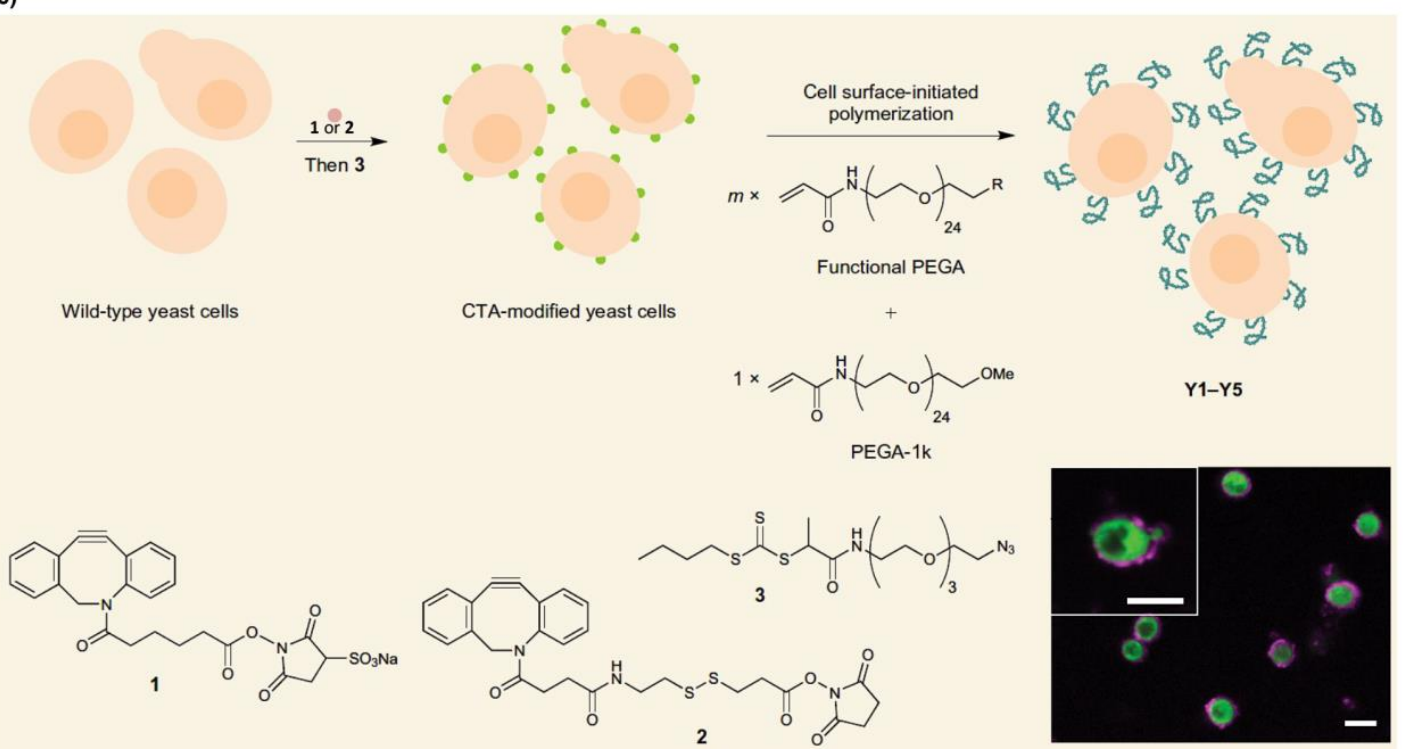

Fig. 1. Immobilization of materials on the cell membrane with therapeutic potential. (a) Cell capture and release from poly(acrylamidophenylboronic acid)-silicon nanowires triggered by $\mathrm{pH}$ and glucose variations. Adapted with permission from ref. 46; Copyright (2013) American Chemical Society. (b) Modification of MSCs with biotinylated SLeX to promote tethering and rolling interactions (on a Pselectin coated surface). Adapted from ref. 52 with permission from Elsevier. (c) Cells modified by surface-initiated PET-RAFT to manipulate cellular interactions; confocal microscopy image demonstrates that modification only occurs at the cell membrane with minimal toxicity (intense green signal). Adapted from ref. 66 with permission from Springer Nature.

The conventional "grafting to" strategies are frequently limited by low polymer grafting efficiency or the use of an excess of reactive polymers for functionalization. Alternatively, "grafting from" approaches have thus emerged to directly engineer the membrane of cells through surface-initiated controlled radical polymerization techniques and improve polymers' properties [64, 65]. Recently, Hawker and colleagues described a cytocompatible and rapid photoinduced electron transfer-reversible addition-fragmentation chain-transfer polymerization (PET-RAFT), as illustrated in Fig. 1c [66]. This light-mediated method enabled the chain growth of PEG-based polymers 
from initiators anchored on the membrane of living yeast and mammalian cells, without compromising cell viability. Moreover, it was possible to control the cellular phenotype by inducing aggregation in the presence of tannic acid via hydrogen bonding interactions.

\section{Cell spheroids and 3D culture}

Biological systems interact through multiple simultaneous molecular contacts that have unique multivalent properties qualitatively different from those displayed by their constituents individually [67]. 2D cell culture has been demonstrated to fail to fully recapitulate the in vivo microenvironment sensed by the cells, which may overlook vital parameters to accurately reproduce and satisfy the structural requirements that complex biological systems demand, including mechanical and chemical cues, cell-cell and cell-ECM interactions [68, 69].

The realization of the limitations of these culture systems contributed to the development of facile reproducible 3D cell culture methods that mimic the native tissue as accurately as possible and provide a powerful platform to understand physiological mechanisms in vitro, study tumor models, gene expression, drug screening and design transplantable organ constructs [70-73]. Cells cultured in 3D systems may exhibit characteristics more relevant to physiological conditions than those on 2D surfaces, including adhesion, mechanics, cytoskeletal organization, proliferation, migration, differentiation, apoptosis, spatial distribution, gene expression, diffusion and response to signaling molecules [74-77].

Multicellular spheroids are now widely exploited models for 3D culture created from single or co-culture methods either matrix-based or scaffold-free - where the cells tend to spontaneously aggregate and self-organize into spherical compact clusters (on non-adherent substrates), which render a simple and reproducible model of the physiological microenvironment [78]. Their formation generally involves: i) the binding of ECM fibers to surface integrins that triggers the aggregation of dispersed cells (early phase); ii) a delay period exhibiting up-regulated expression of cadherin due to cell-cell contacts, and iii) cells compaction into solid aggregates/spheroids driven by the homophilic cadherins adhesion (Fig. 2a) [79]. These structures normally possess an active area of proliferating cells at the periphery, with quiescent/necrotic cells in the inner part, which is evidenced for spheroids with diameters typically above $200 \mu \mathrm{m}$ that 
are associated with oxygen and nutrients deprived centers (Fig. 2b) [80]. Fundamentally, spheroids can capture architectural and functional characteristics of the native tissue and modulate therapeutic activities by secreting paracrine-signaling factors. Cells are surrounded by the ECM which provides distinct biomechanical and biochemical cues, and are exposed to complex molecular diffusion patterns, which can determine cell differentiation, proliferation and homeostasis [81].

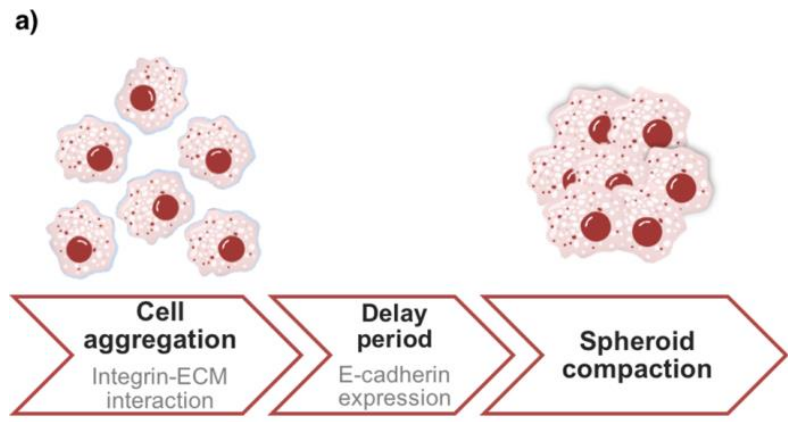

b)

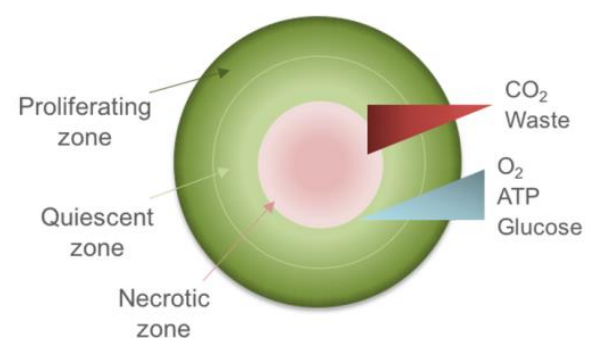

Fig. 2. (a) Spheroids formation process and (b) pathophysiological gradient model.

Over the years, various techniques have been employed to fabricate cell spheroids, which include hanging-drop culture, non-adherent surfaces, micromolding, spinner flasks, microfluidics, polymer scaffolds or external forces [82-88]. An interesting process for cell spheroid fabrication and delivery in situ may rely on temporary hydrogel-mediated cell immobilization followed by the dissociation and release of these aggregates $[89,90]$. For instance, Zhang and co-workers developed an injectable galactosylated hydrogel that solidifies at physiological temperature to reversibly encapsulate hepatocyte spheroids within two weeks and promote liverspecific functions, which could be harvested from the scaffold by cooling down to room temperature without significantly affecting their viability [91]. Parameters such as throughput, size and cell number, incubation time, reproducibility, specialized equipment and cost should be considered when selecting the optimal process $[92,93]$. 
Although cell spheroids have been mostly investigated in vitro, it is expected that they provide a roadmap for future advances in cell therapies and tissue engineering, which would expedite the pre-clinical use of biomaterial-cell ensembles, improving the quality and accessibility of the disease treatments and therapeutic efficacy. In the last seven years, studies involving spheroids' implantation in vivo (rodent models) have evolved with focus on musculoskeletal, cardiovascular, hepatic and endocrine applications by evaluating, among other parameters, cell retention, survival and differentiation, regenerative efficiency or vascularization potential [94-102].

\section{Polymer-mediated cell membrane remodeling for cell aggregation}

As previously mentioned, the functionalization of the cellular interface with exogenous polymeric-based materials has been exploited to regulate cell communication and adhesion, trigger cellular aggregation and mimic tissue-like organized structures by turning the cells into suitable "building blocks" to investigate cell-cell interaction and recognition with interest in biosensing, cell-based therapies and tissue engineering. Chemical derivatization of the cell membrane constitutes a powerful approach to selectively induce the aggregation of cell populations in highly controlled manner; the studies on RBCs pioneered the clinical interest of researchers for these reversible cell assembly strategies [103-106]. The procedures for the direct installation of these (nano)materials range from covalent crosslinking to ligand-receptor mediated, hydrophobic and electrostatic interactions.

The construction of complex 3D multicellular structures in vitro is an area of intensive research dedicated to the generation of spheroids, and ultimately, artificial organoids which resemble the architecture, composition, cellular organization and genetic signature of human miniaturized organs [73].

An interesting strategy was reported by Yousaf and co-workers who investigated a scaffold-free co-culture cardiac tissue model based on the engineering of the cell membrane by liposome fusion to install bio-orthogonal functional groups $[107,108]$. Cardiomyocytes, cardiac fibroblasts and human umbilical vein endothelial cells (HUVECs) decorated with ketone and oxyamine groups at the surface were rapidly clicked together via stable oxime bonds (Fig. 3a). This tissue-like assembly was able to beat synchronously without any external electrical stimulation due to high cell density and efficient development of cellular junctions. In a following study, the same group 
engendered liposome fusion to create a photo-active and bio-orthogonal cell membrane for remotely-controlled spatial and temporal cellular assembly and disassembly upon UV light irradiation, since the ligation tether contained a photo-cleavable group. Such an approach allowed for the modulation of cell adhesion and production of clusters of fibroblasts and hMSCs (within 3 hours) and multi-layered microtissue structures (5 days) $[109,110]$. This strategy also inspired the researchers to use the liposome fusion to functionalize the cell membrane of fibroblasts with fluorescent RGD (Arg-Gly-Asp) peptides, which could recognize and adhere to integrin-expressing fibroblasts and form oriented tissue microlayers [111]. Cell metabolic assays revealed that the cells still remained active 5 days after lipid fusion.

a)

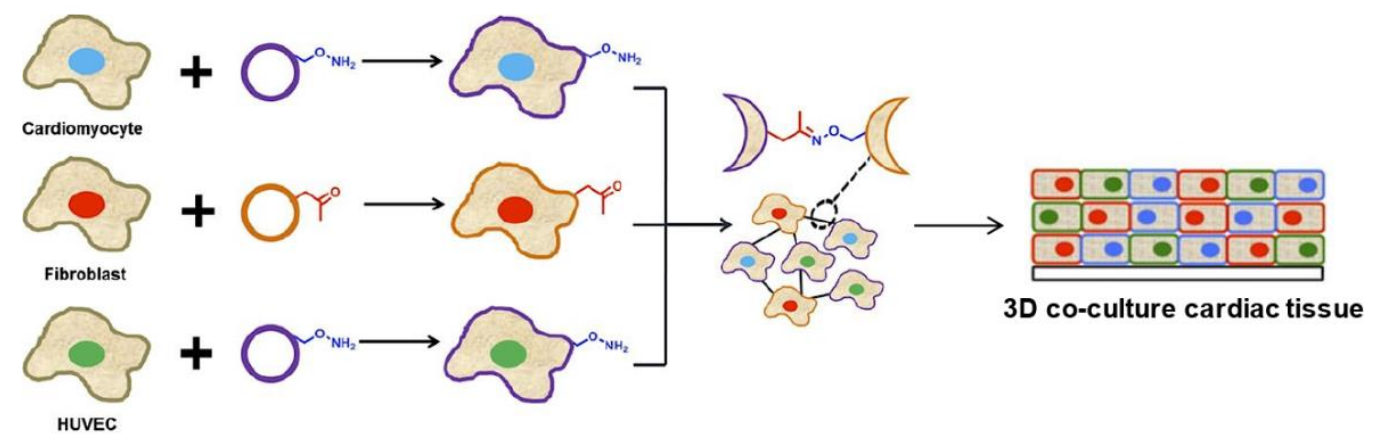

b)
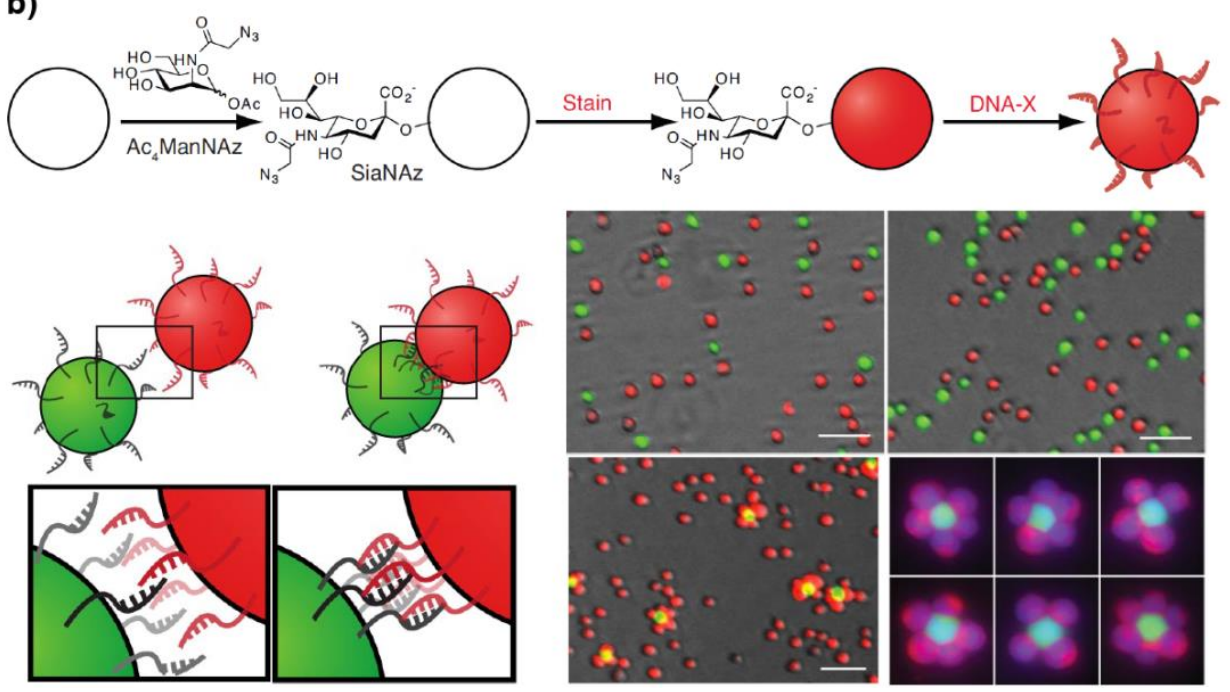

Fig. 3. (a) Schematic illustration of the formation of scaffold-free cardiac microtissue combining cell membrane engineering and bioorthogonal chemistry. Adapted from ref. 108 with permission from Springer Nature. (b) Attachment of complementary DNA strands onto metabolic-engineered fluorescent Jurkat cells to induce their assembly into 3D spherical structures (scale bars: $50 \mu \mathrm{m}$ ). Adapted from ref. 114, Copyright (2009) National Academy of Sciences. 
The functionalization of the cell membrane with DNA helices can afford selective cell-cell interactions driven by the high affinity hybridization of two complementary strands. To this end, Bertozzi and Francis groups reported seminal works employing metabolic oligosaccharide engineering to anchor azidosialic acid on the surface of the cells [112], which could then react with triarylphosphine-modified single-stranded DNA through Staudinger ligation, to trigger cellular assembly under physiological conditions [113]. The researchers elegantly demonstrated that Jurkat cell populations modified with complementary DNAs could be reversibly assembled into microtissues in a well-defined manner (i.e. by adjusting the DNA density on the surface, DNA sequence and cell concentration), where (non-modified) control cells showed limited cell aggregation [114]. When fluorescence oligonucleotides were employed, they observed DNA strands clustered at the cell interface, confirming their specific role in the aggregation process (Fig. 3b). More importantly, the researchers verified that the cells within the assembled microtissues could crosstalk by paracrine mechanisms (that is a prerequisite for the formation of functional tissues). The same group also reported the covalent reaction of a NHS-PEG-maleimide crosslinker with primary amino groups present on the membrane proteins followed by the conjugation of thiolated DNAs via maleimide chemistry [40]; RBCs, primary T-cells and cardiomyoblasts could be captured and attached to a predefined substrate to investigate the formation of myotubes capable of spontaneous contraction. More recently, non-covalent methods were similarly employed to intercalate lipid-conjugated DNA derivatives on the plasma membrane to rapidly and specifically aggregate the cells in a microsized pattern substrate; multicellular spheroids could then be formed after 24 hours with controlled size, shape and spatial organization to explore collective cell behaviors and morphologies [115].

In a similar context, Castro et al. described the attachment of DNA origami nanostructures to the surface of various cell lines (including suspended, adherent and primary cells), using cholesterol-conjugated oligonucleotides as amphiphilic anchors, to create a programmable platform to probe spatially and reversibly cell binding [116].

Yun and co-workers developed a more intricate "cell-gluing" system based on metabolic glycoengineering to install tetrazine and trans-cyclooctene groups on the surface and posterior click chemistry conjugation to form covalently-bound cell complexes, which exhibited minimum cytotoxicity [97, 117]. Yusa and co-workers reported an alternative, but also interesting approach, where methacryloyl groups were 
introduced metabolically into carbohydrates on the surface of HL-60 mammalian cells followed by the immobilization of a thermoresponsive thiol-terminated $\operatorname{poly}(N-$ isopropylacrylamide) (PNIPAAm) polymer by UV irradiation (without affecting significantly the cell viability). When the temperature increased to $37^{\circ} \mathrm{C}$, i.e. above polymer's lower critical solution temperature (LCST), the cells spontaneously aggregated, after 30 minutes, owing to the hydrophobic effect of PNIPAAm [118].

Recently, boronic acid chemistry was employed by our group as a simple and generic cell membrane remodeling strategy to induce and remotely control the rapid formation of aggregates in mammalian cells (including fibroblasts, cardiomyoblasts and cancer cell lines) and bacterial strains by exploring bio-orthogonal ligand-receptor multivalent interactions [119-122]. Accordingly, thermoresponsive PBA-based copolymers, at micromolar concentrations, could regulate cell aggregation driven by the intercellular crosslinking of neighboring cells through the formation of diol-boronate ester bonds with sialic acids present on cell surface glycoproteins, and by the hydrophobic interaction of the polymers via coil-to-globule phase transition at $37^{\circ} \mathrm{C}$ as shown in Fig. 4. The engineered cells could self-organize into clusters in under 30 minutes, using conventional cell culture conditions, and form well-defined and homogenous spheroids with controlled size at variable rate when cultured for 2 days (in non-adherent plates) [120]. The proposed method did not compromise cell viability, exerted robust kinetics and accelerated the formation of spheroids compared to nontreated cells, where it is reversible by glucose addition or temperature variation. Similarly, when the cells were modified with a thermoresponsive NHS-activated ester oligo(ethylene glycol) methacrylate copolymer, the formation of large cell aggregates was induced due to the coil-to-globule phase transition of the polymer above its LCST [119]. Therefore, this work overcomes certain deficiencies presented by current methods such as variable spheroids diameter, laborious handling, time consuming, lowthroughput and cost. In addition, we have demonstrated that it is possible to exploit these cell-polymer interactions to form bulk injectable cellular glues with intriguing rheological properties that can be adjusted by thermal or light stimuli (see below). 
a)
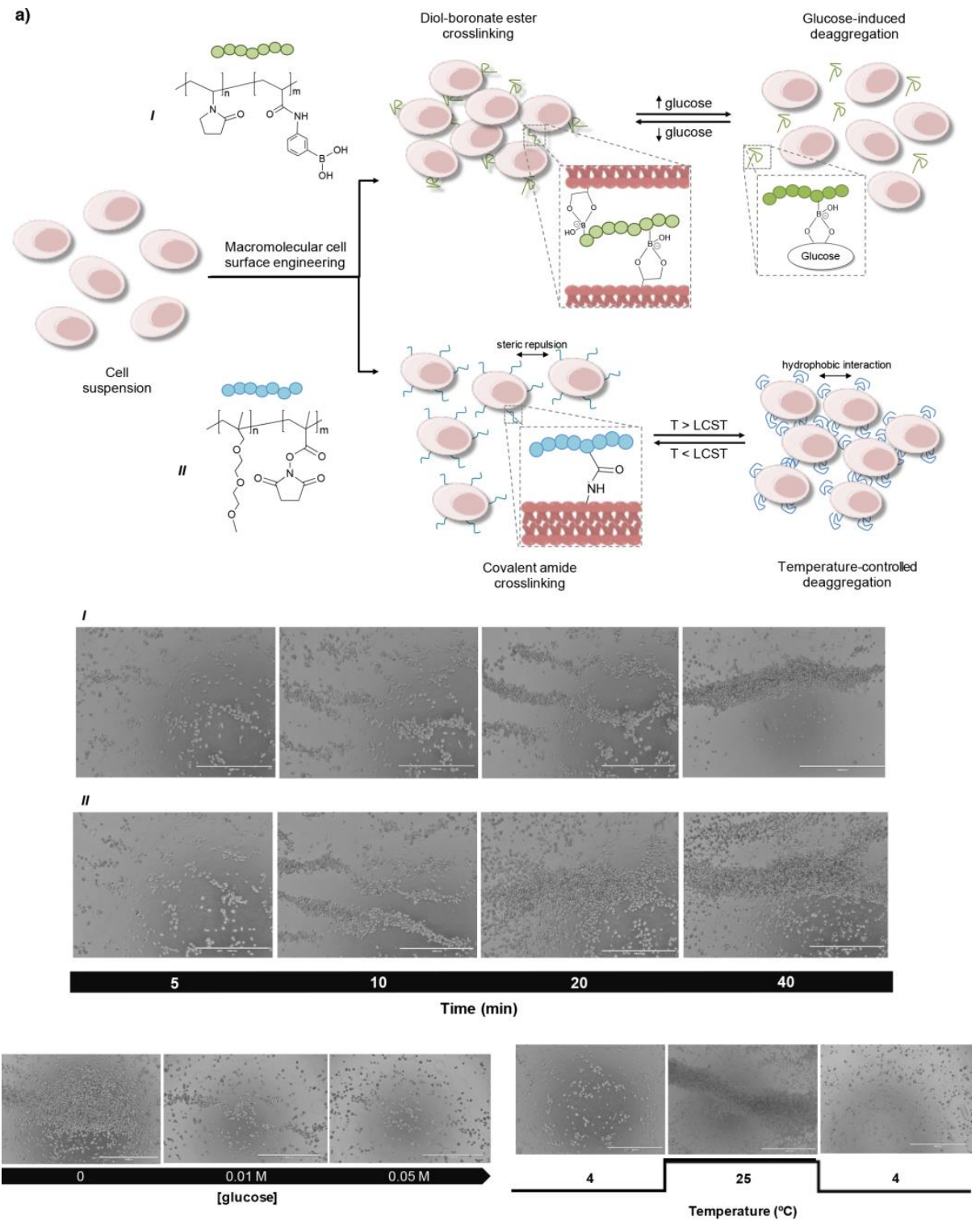

b)
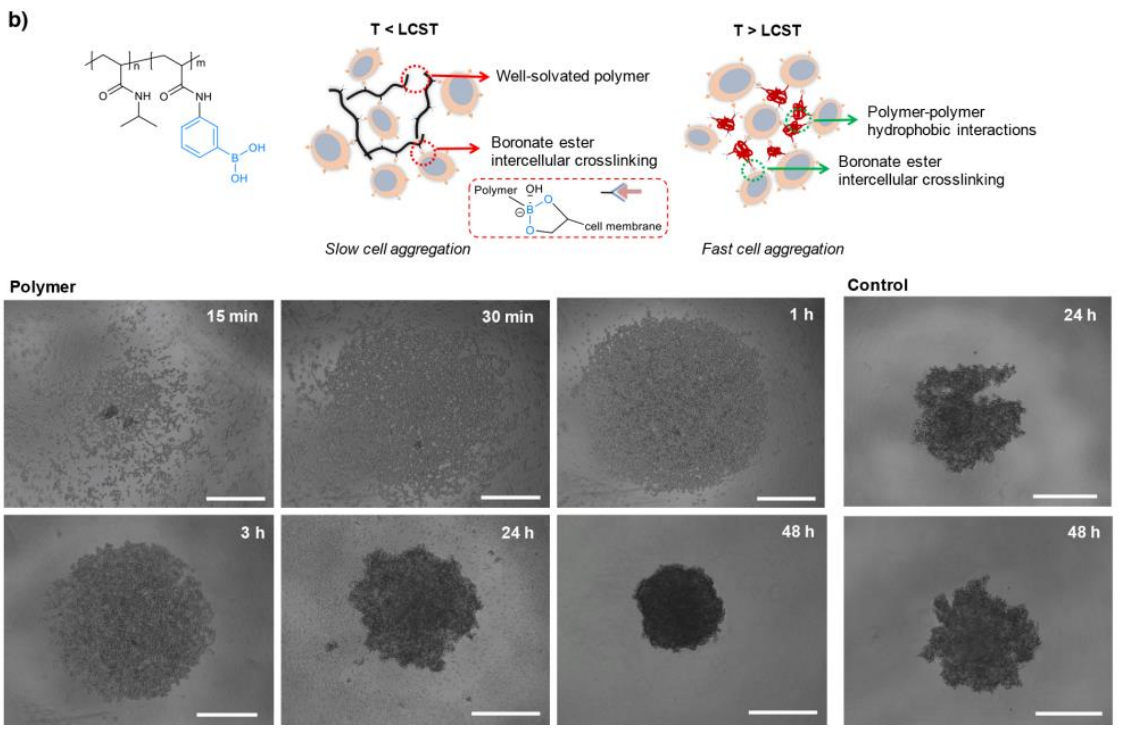

Fig. 4. Illustration of macromolecular cell surface remodeling approaches employed (a) to control the rapid and reversible cellular aggregation with different stimuli (scale bars: $1000 \mu \mathrm{m}$ ), and (b) to form uniform cell spheroids using a thermoresponsive boronic acid copolymer (scale bars: $500 \mu \mathrm{m}$ ). (a) Adapted from ref. 119 with permission from the Royal Society of Chemistry. (b) Adapted with permission from ref. 120, Copyright (2016) American Chemical Society. 
Ligand-receptor mediated cellular aggregation strategies utilizing RGD peptides or biotin-(strept-)avidin type of interactions have been explored by several researchers [123-125]. Early studies of the Saltzman group described the (asymmetrical) aggregation of neuroblastoma cells and fibroblasts in serum-free culture, using an orbital shaker, promoted by PEG-RGD terminated polymers through peptide specific binding to complementary cell surface integrin receptors [126, 127].

In another study, Meier described the synthesis of poly(ethylene oxide) (PEO) modified with a hydrophobic cholesteryl group at one end and a hydrophilic biotin group at the other; the copolymer (at a relatively high concentration of $3 \mathrm{mg} \mathrm{mL}^{-1}$ ) could be anchored in the lipid membrane through hydrophobic interaction and the cells aggregated reversibly when incubated for 4 hours with streptavidin [128]. Interestingly, it was verified that the biotinylated PEO chains should have a minimal distance of approximately $15 \mathrm{~nm}$ from the plasma membrane to overcome the steric effect of the glycocalyx and permit the effective binding of streptavidin molecules. Jiang and coworkers took advantage of biotin-streptavidin interactions to develop 3D multilayered tissue-like structures [129]. Biotinylated cells were coupled to streptavidin-coated adherent cells and added sequentially to form a multilayer within one hour. The deposition of a bilayer of HUVECs and Jurkat cells on a stress-induced rolling membrane could then form 3D tubular structures that mimic the intima part of blood vessels walls (Fig. 5a). The same principle was earlier investigated by Shakesheff et al. who attached biotin molecules on the cell membrane of myoblasts and further added an avidin solution to induce their aggregation within 75 minutes at room temperature under agitation [130]. Prior to this step, biotinylation of the cells was performed through periodate oxidation of the vicinal diols of sialic acid residues on the cell surface to form aldehyde groups which could be used to selectively bind biotin hydrazide by hydrazone bond formation, without observing significant cell toxicity [131]. Alternatively, the same group recently described holographic optical tweezers-based cellular micromanipulation to generate defined 3D patterns stabilized by using avidin-biotin cell crosslinking; this technique allowed for the chemical and spatiotemporal control of individual or groups of cells, which can be applied to study complex stem cell niches [132].

The LbL technique for the fabrication of polyelectrolyte multilayers (PEMs) has also been employed in tissue in vitro modeling and cell immobilization [133]. Rubner and co-workers reported on injectable cellular "backpacks", consisting of hyaluronic 
acid (HA)-containing multilayer microparticles, which could be attached by Coulombic forces to the membrane of one or more cells to form small aggregates. Their size was affected by the ratio of cells to backpacks $(R)$ and the backpack diameter $(d)$ aggregates' size monotonically decreased with $R$ and increased with $d$ [134]. LbL assembly was also employed by Akashi and colleagues to prepare nanometer ECMmimicking films on the surface of fibroblasts, composed of fibronectin and gelatin, to promote integrin-mediated adhesion between neighboring cells (Fig. 5b). The subsequent deposition of cell populations drove the construction of organized 3D cellular multilayers, under 6 hours, which can resemble the architecture of blood vessels [135], vascularized cardiac tissue [136], or liver tissue [137]. More recently, this research group reported the fabrication of mature pancreatic $\beta$-cell spheroids within 3 days, where the LbL cell coating (comprising gelatin and fibronectin) enhanced the insulin secretion ability in vitro (Fig. 5c) [102]; in addition, diabetic mice transplanted with the engineered spheroids exhibited lower blood glucose levels and improved glucose sensitivity after intraperitoneal glucose stimulation compared to controls.

Fery et al. exploited a microcontact printing process with interest in biosensing to first coat yeast cells with PEMs (poly(allylamine hydrochloride) and poly(styrenesulfonate)), and later to immobilize the cells on patterned substrates while maintaining their viability [138]. Paunov and co-workers showed the formation of spherical yeast cells clusters by colloid interactions based on the microbubble templating of cells coated with cationic polyelectrolytes [139, 140]; these cell assemblies of hollow-shell architecture, called "cellosomes", were created due to the attraction of the polycation-coated cells by the net negative surface charge of the microbubbles. 
a)

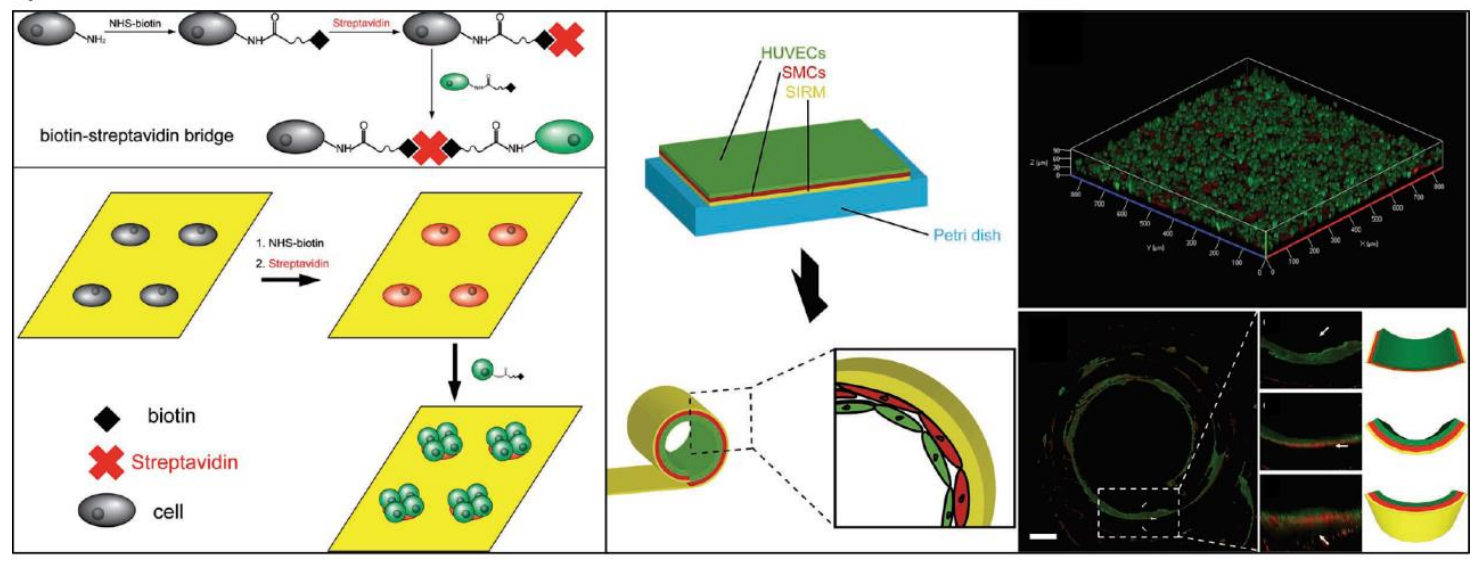

b)

$3 \mathrm{D}$ multilayer

$\checkmark: F N \_:$Gelatin

1) Layer-by-layer assembly
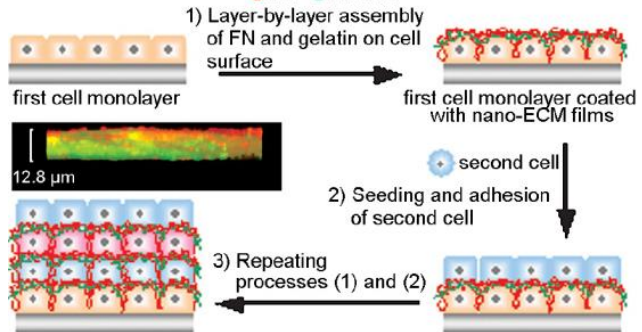

( second ce Seeding and adhesion sis. Bilayer

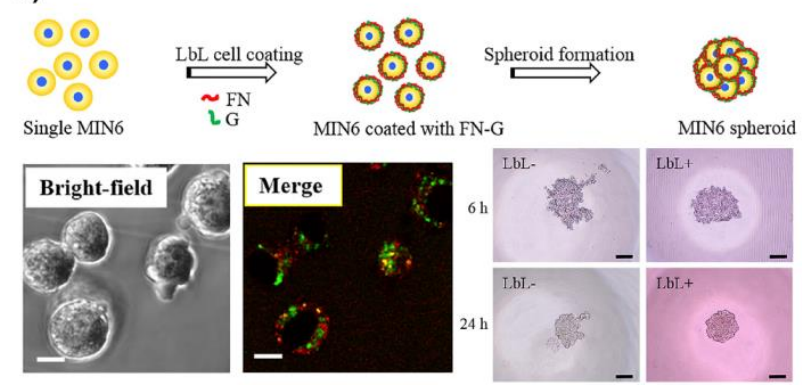

c)

Fig. 5. (a) Schematic illustration of cell aggregation promoted by biotin-streptavidin type of interaction to fabricate cell sheets mimicking a tubular wall (scale bar: $200 \mu \mathrm{m}$ ). Adapted with permission from ref. 129; Copyright 2013, Wiley-VCH Verlag GmbH \& Co. kGaA, Weinheim. Layer-by-layer cell coating can also be applied to fabricate (b) 3D cellular multilayers and (c) $\beta$-cell spheroids (left, scale bars: 10 $\mu \mathrm{m}$; right, scale bars: $200 \mu \mathrm{m}$ ). (b) Adapted with permission from ref. 135; Copyright 2007, Wiley-VCH Verlag GmbH \& Co. kGaA, Weinheim. (c) Adapted from ref. 102 with permission from Elsevier.

Caggiano and co-workers synthesized a maltol-derived hydrazide that was installed on the cell surface through reaction with aldehyde groups previously introduced on the membrane using the well-known mild oxidation of sialic acid moieties [141]. When $\mathrm{Fe}^{3+}$ ions were added to the serum-free suspension, cancer cells started to aggregate after 10 minutes, owing to the selective maltol's high affinity for $\mathrm{Fe}^{3+}$ ions. However, in complete culture medium, cell aggregation was prevented presumably due to iron-chelating proteins, such as transferrin. It was also observed that the aggregates' size increased proportionally with time and to the increase of $\mathrm{Fe}^{3+}$ concentration up to a critical value $(100 \mu \mathrm{M})$.

$\mathrm{Yu}$ and colleagues developed a hydrazide-functionalized inter-cellular linker polypropylenimine hexadecaamine dendrimer (DAB-AM-16) - which could react with the aldehyde groups of metabolically engineered HepG2 cells' surface and trigger aggregation [142, 143]. This dendrimer presented higher cell aggregation efficiency 
compared to the dendrimers with fewer arms and no charge, and facilitated spheroids' formation at lower linker concentrations $(10 \mu \mathrm{M})$, which minimized the toxicity. The cell aggregates maintained their morphology and cellular functions over a 7-day culture period, even as the polymer linker gradually disappeared from the surface after 2 days. Inspired by the previous results, the researchers later described an oleyl-PEG derivative conjugated to 16 arms-DAB to rapidly assemble hepatocarcinoma cells ( $c a .30$ minutes in orbital shaker) [144]. The positively charged dendrimer concentrated the linker onto the negatively charged cell surface to facilitate the insertion of the oleyl groups into the membrane to produce cell spheroids with high viability; their rate of formation was accelerated by increasing the linker concentration (up to a critical value of $1 \mu \mathrm{M}$ ), although the morphology was not predominantly uniform. The Taguchi group reported the aggregation of pancreatic $\beta$-cells based on the functionalization of cell membranes with a polymeric crosslinker composed of two distinct units - PEG derivative with oleyl groups at both ends [145]. The crosslinker could anchor to the phospholipid bilayer and trigger cell aggregation via hydrophobic interactions within 3 days (Fig. 6a). Moreover, the resultant spheroids showed enhanced insulin secretion and mRNA expression of Ecadherin with increasing crosslinker concentration (up to $2.5 \mathrm{mg} \mathrm{mL}^{-1}$ ), although their formation proved to be more efficient in the absence of serum. The same group employed a similar strategy to promote the generation of spheroids of HepG2 cells, whilst it exhibited higher ammonia elimination and albumin secretion [146, 147].

Another strategy from Kim and co-workers employed electrospinning fabricated poly(lactic-co-glycolic acid) nanofibers to induce the formation of small cellular spheroids possibly driven by the adsorption of vitronectin and fibronectin from the serum on the fibers. The incubation of fibroblasts and embryonic kidney cells with the nanofibers improved the efficiency of spheroid formation, mainly during the first 12 hours of the process, as well as increased the average diameter of the spheroids. It was also shown that FAK gene expression (associated with cell adhesion) was augmented in the presence of the polymer nanofibers when compared to controls [148]. Otherwise, the Tae group used a lipid-conjugated heparin to form cell aggregates after 30 minutes by shaking the suspension, although this interaction is relatively weak when compared with other systems where the shape could be controlled based on the templates used [149]. 

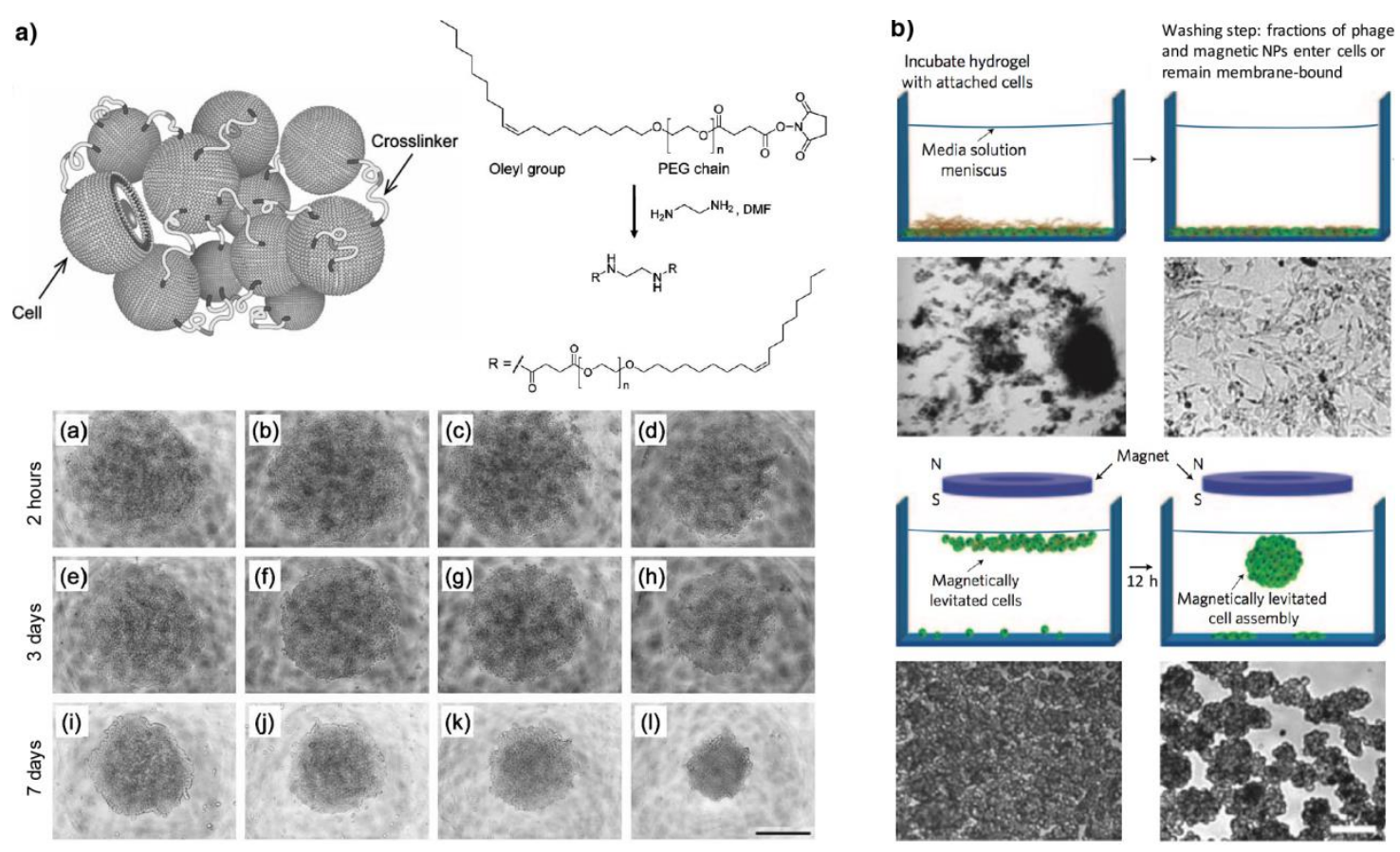

Fig. 6. (a) Cell aggregation process and subsequent spheroid formation induced by a hydrophobicterminated polymeric crosslinker (seeding density of $1 \times 10^{5}$ cells per well and scale bar represents 1 $\mathrm{mm}$ ). Adapted from ref. 145 with permission from Elsevier. (b) Formation of spheroids based on magnetic cell levitation. The incubation of cells with iron oxide nanoparticles elicit their aggregation when an external magnetic field is applied (scale bars: $30 \mu \mathrm{m}$ ). Adapted from ref. 150 with permission Springer Nature.

The functionalization of the cell surface with polymeric particles provides further means to trigger contactless tissue assembly driven by external fields, which may help to recreate signaling cues or sense the local microenvironment. A noteworthy illustration of this concept has been explored by several researchers who designed magnetized cells that can be organized into random clusters, spheroids or sheets (Fig. 6b) [150-153]. For instance, Alsberg et al. reported biocompatible albumin-coated magnetic NPs that decorate human endothelial cells' surface and when exposed to an external electromagnetic field, they could form chain-like cell assemblies by a negative magnetophoresis process (i.e. motion induced by the magnetic field on a particle) [154]. After the ferrofluid removal, the cells could adhere to a substrate and grow normally. Magnetically-labelled MSCs with anionic citrate-coated maghemite $\left(\gamma \mathrm{Fe}_{2} \mathrm{O}_{3}\right)$ NPs could also be used to form aggregates of defined sizes and shapes, such as spheres, rods or sheets, in order to create cellular patterns for stem cell differentiation into chondrocytes, as reported by Wilhelm and co-workers [155]. In a similar context, Velev et al. showed that colloidal microparticles, namely lectin-coated paramagnetic particles, anchored to the plasma membrane by biospecific or electrostatic interactions, stimulated aggregation 
of eukaryotic yeast and fibroblast cells on a chip to yield 1D chains or 2D arrays when an electric field was applied - dielectrophoresis process [156]. Salem and colleagues designed a cell-microparticle hybrid system to enhance cell-cell interactions by preparing biotinylated PLA-PEG microparticles that bound to the previously biotinenriched membrane of human embryonic kidney cells with avidin as the bridging protein [157].

\section{Cellular glues}

Inspired by cell-cell communication and the interaction between cells and the ECM in the complex biological environment, researchers have explored the ability of cells and biopolymers to coordinate through multiple adhesive connections to form macroscopic "cellular glues", which could create cell-rich gel type biomaterials for tissue regeneration or the formation of millimeter-sized 3D spheroids. The cells serve as active structural elements within the polymer matrix, where each polymer chain is attached simultaneously to multiple ligands of the surface of adjacent cells creating a 3D network (Fig. 7). This approach is highly appealing in that it minimizes the need for use excess of biomaterial which is only utilized at the cell membrane interface; potentially, this methodology mitigates toxicity issues and could facilitate better integration with the surrounding tissues at the site of implantation.

In this context, an interesting example was reported by Mooney et al. who prepared a RGD-modified alginate polymer that was mixed with living prosteoblasts (at a concentration of $1.5 \times 10^{8}$ cells $\mathrm{mL}^{-1}$ ) [158]. The integrin receptors on the cell surface could bind and crosslink multiple polymer chains of the RGD-functionalized alginate that stabilized the polymer-cell suspension and formed a soft gel $\left(1<\mathrm{G}^{\prime}<20 \mathrm{~Pa}\right)$ with mechanical properties that were dependent on the cell density used. Meier and coworkers described cell-material crosslinked networks formed by polymers bearing hydrophobic end-groups, i.e. $\alpha$ - $\omega$-cholesterol-modified poly(oxyethylene), that could be inserted into the hydrophobic region of the lipid bilayer and interconnected the cells to form gels with a storage modulus around $100<\mathrm{G}^{\prime}<500 \mathrm{~Pa}$ [159]. More recently, Raghavan et al. synthesized hydrophobically-modified chitosan or alginate polymers that were anchored on the membrane of HUVECs via hydrophobic effect and capable of gelling the suspensions $\left(1<\mathrm{G}^{\prime}<10 \mathrm{~Pa}\right)$, without affecting their viability [160]. 
Our group also reported the formation of macroscopic cell-laden gels, using a boronic acid-based copolymer and a thermoresponsive succinimide-based copolymer, under physiological conditions within seconds [119, 161]. The cell glues (G' 200 Pa) could be reversibly turned to their corresponding sol state and release their cellular cargo either by the addition of glucose (that saturates and dissociates the boronic acid groups from cell-bound diols), or by lowering the temperature below the LCST (hydrophilic state of the polymer). It was observed that the variation of the polymer-cell ratio feed could influence the gelation behavior but the soft gels could remain stable for hours without significant physiological alteration of the cells tested.
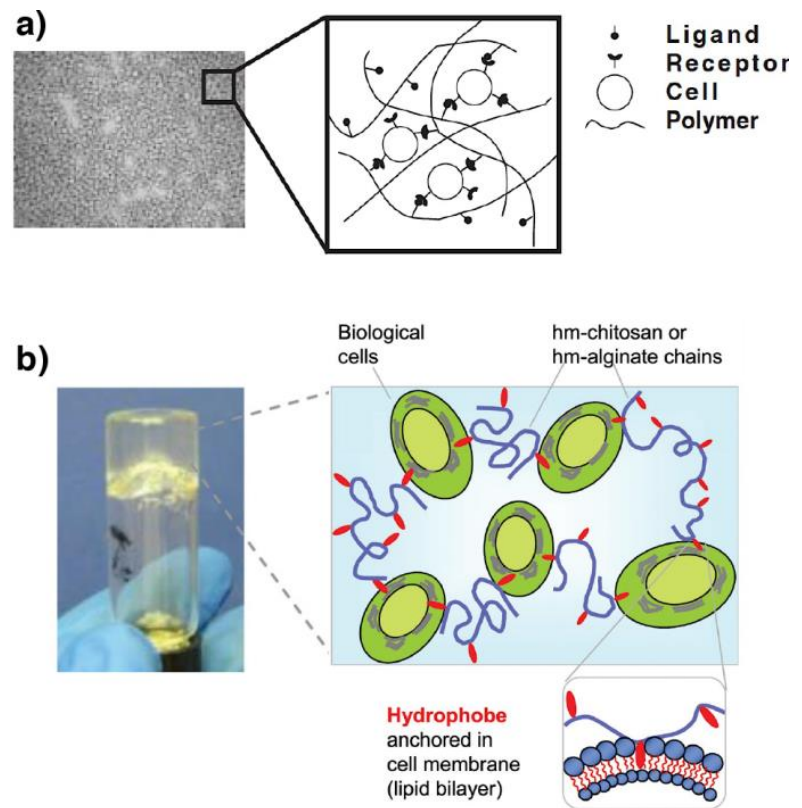

Fig. 7. Depiction of cell "gelation" mechanisms. (a) Reproduced with permission from ref. 158; Copyright 2003, Wiley-VCH Verlag $\mathrm{GmbH} \&$ Co. kGaA, Weinheim. (b) Adapted from ref. 160 with permission from the Royal Society of Chemistry.

\section{Organ/tissue printing using self-assembled multicellular spheroids}

The exciting field of 3D printing stands as an (ex vivo) tool capable to create complex tissue architectures and allows for a precise spatiotemporal control of organoids fabrication [162, 163]. Bioprinting allows for the accurate positioning of different types of living cells, polymers, drugs or growth factors in a $3 \mathrm{D}$ environment using scaffold-based (e.g., hydrogels and microcarriers) or scaffold-free (e.g., cell aggregates) bioink materials, using computer-aided design, which can closely replicate physiological functions and architecture of target tissues, and improve human models 
for organ transplantation and disease modeling [164]. Scalability and suitability for automation with bioprinters are also attractive aspects of directed tissue assembly technologies.

As 3D bioprinting (either laser-, extrusion- or droplet-based) becomes more sophisticated, the selection of appropriate biomaterials with tunable properties can determine the mechanical, chemical and physical properties of the designed structure; rheological properties, degradation behavior, printing speed and cell density vary according to the bioprinting technique used, which can affect the cellular viability and proliferation [165, 166]. Tissue and organ models of kidney, liver, heart, blood vessels, lungs, skin, cartilage and bones are already exploited for drug testing and in vitro assays [167].

From a biological perspective, organ development during early morphogenesis relies on intrinsic cellular adhesion mechanisms and tissue fusion, being these fundamental principles of 3D printing technologies. Bioprinting of cell spheroids, through scaffold-free approaches, has been envisioned as a promising solution for the fabrication of functional tissues in shorter time with multifarious architectures since cellular aggregates, under appropriate conditions, can be used as self-assembling building blocks for regenerative medicine applications [168-171]. Scaffold-free bioprinting can thus offer relatively high cell density initially without the inclusion of biomaterials.

An early example was reported by Forgacs and co-workers who developed cellular spheroids of controllable diameter $(300-500 \mu \mathrm{m})$ of smooth muscle cells and fibroblasts, which could be deposited layer-by-layer onto a molding template. The postprinting tissue fusion and maturation of the bioinks originated elongated multi-layered structures that resembled segments of branched vascular trees as small diameter blood vessels (Fig. 8a) [172]. Following a similar approach, Morita et al. later reported the printing of small caliber tubular tissues, composed of HUVECs, aortic smooth muscle cells and dermal fibroblasts, from cell spheroids after four days [173]. The researchers cultured the tubular tissue in a perfusion system and implanted it into the abdominal aortas of nude rats, showing that the inner surface of the vascular constructs underwent endothelialization. Hibino and colleagues fabricated 3D bioprinted cardiac tissue by assembling cardiospheroids consisting of human induced pluripotent stem cell (iPSC)derived cardiomyocytes, human ventricular cardiac fibroblasts and HUVECs on a needle array (Fig. 8b) [174]. The patches developed could beat spontaneously (within 
three days) and exhibited initial engraftment and vascularization when implanted in vivo. More recently, Mironov and co-workers reported a bioprinted vascularized mouse thyroid gland construct from embryonic tissue spheroids, which could restore thyroid homeostasis after grafting under the kidney capsule of hypothyroid mice [175]. Another noteworthy method based on a coaxial extrusion and microinjection technique introduced tissue strands (obtained through aggregation of cells) as scalable bioinks that facilitated rapid fusion and maturation, and could be printed in solid form without the need for a mold support or liquid delivery medium during extrusion [176]. Cartilage mature strands were nearly completely fused into a single tissue patch after 7 days, implanted into ex vivo osteochondral tissue defects and were able to undergo remodeling effect within the host tissue [177].

Bioinspired microtissues are in the early phase of prototyping and development. Despite the recent progress, this technology still presents different limitations, which include the cost, bioprintability, the difficulty of producing tissues with clinically relevant resolution, complexity, size and shape (such as vasculature), viability and tissue fusion culture period [178].

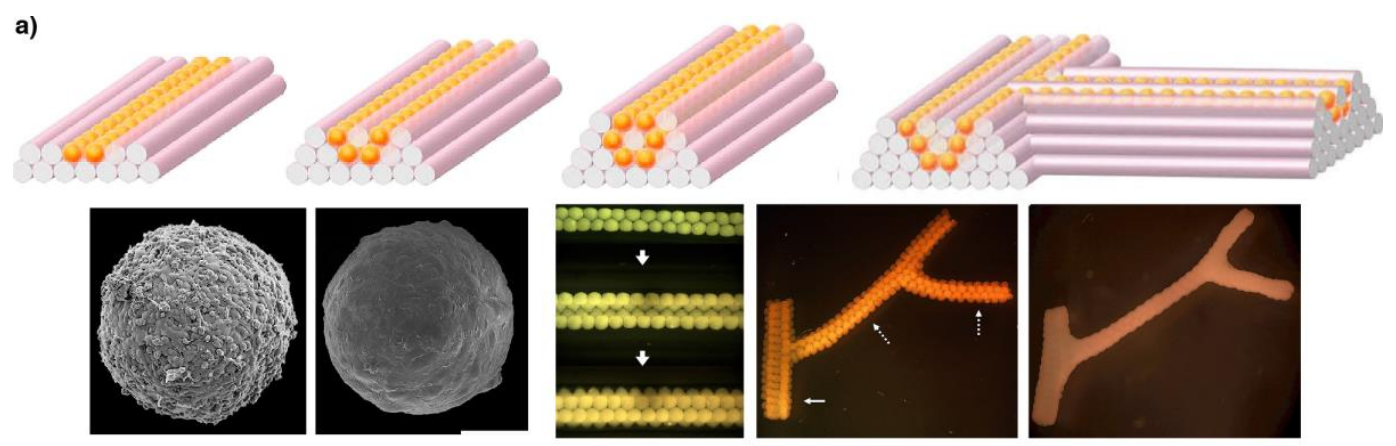

b)

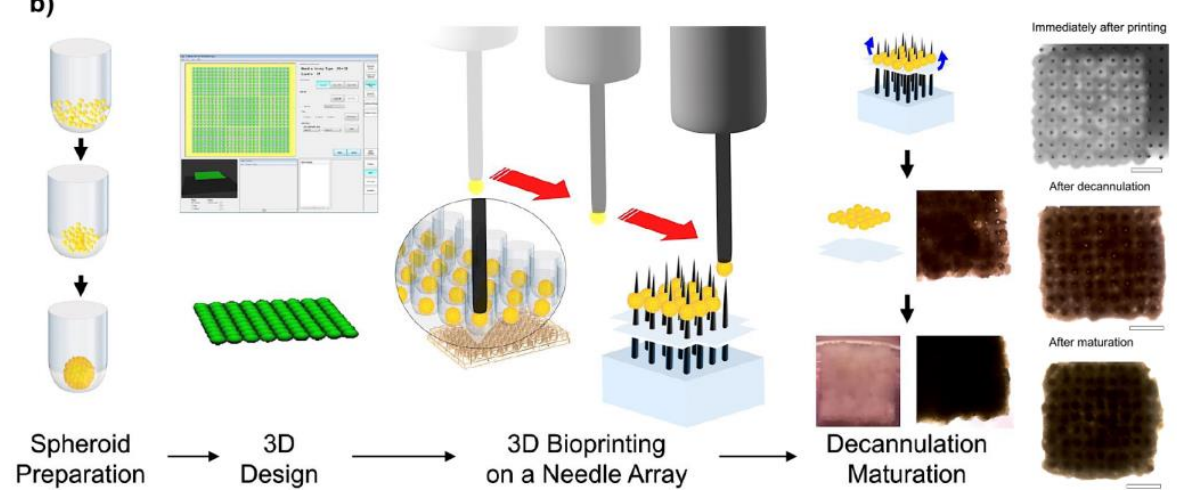

Fig. 8. (a) Bioprinting of tubular structures from multicellular spheroids: layer-by-layer deposition into a template and posterior spheroids fusion to form a branching tube (scale bar: $100 \mu \mathrm{m}$ ). Adapted from ref. 172 with permission from Elsevier. (b) Overview of a biomaterial-free 3D bioprinting process employed to fabricate cardiac patches from cell aggregates (scale bars: 1000 $\mu \mathrm{m})$. Adapted from ref. 174 with permission from Springer Nature. 


\section{Conclusions}

Remodeling of the cell membrane with functional biomaterials has only recently emerged and is likely to impact emerging technologies that can be used for therapeutic and diagnostic purposes, i.e. in disease 2/3D in vitro modeling, cell therapeutics and precision medicine [179-182], cell sorting and cryopreservation technologies [183, 184]. In parallel, it is necessary to thoroughly study the long-term effect of cell surfaceinteracting materials and underlying processes to reduce any negative impact on cellular functions. Although some of the methods previously discussed have clearly demonstrated preclinical potential, non-genetic cell engineering technologies are still in their infancy and none have been translated into the clinic to date. Irrespective of the disease type, the production of cell-based therapeutics requires standardized, safe and cost-effective scale-up production processes.

The development of cell-material ensembles is challenging but promising as it is possible to achieve a level of functional sophistication and therapeutic utility unfeasible using solely synthetic chemistry. To this end, biocompatibility, permeability and diffusion of nutrients, mechanical properties, rate of biodegradation and cell release, route of administration, reproducibility and easy manipulation by the clinicians are critical design criteria to take into consideration $[185,186]$. It is critical to further investigate the localization, stability and sensitivity of the immobilized materials, and how membrane turnover and cell division affects their accessibility. Consequently, the strategies chosen should generate minimal alterations on the biological activity of the cells but confer new functionalities to the system, which can facilitate new insights into tissue engineering. These approaches may aim for targeted delivery, protection of the cells against physical stress, camouflaging surface antigens (reduce immunogenicity), tracking control of cellular processes and promoting cell signaling/recognition, or intercellular interactions. Redesigning the cell membrane with functional materials will continue to impact the cell fate and functioning to foster technologies that can be used for therapeutic and diagnostic purposes, bearing in mind that response efficacy and translational feasibility are fundamental criteria for their success at the clinical setting.

From the previous discussion, it is emerging that spheroid models with tailored characteristics can be used to direct tissue fusion and potentiate the development of living functional prototissues, for example, with the use of 3D bioprinting and other microfabrication methodologies. The concept of computerized layer-by-layer 
biofabrication of human tissues and organs using cell spheroids as building blocks or cellular glues as bioinks was proposed in the last decade and has been gradually evolving; hence, it is likely that even more intricate hierarchical living structures will emerge, which may pave the way towards the envisioning of tissue and organ biofactories for on-demand bioapplications spanning from cell therapeutics to diagnostics, organ transplantation and beyond.

\section{Acknowledgments}

The authors would like to acknowledge the financial support of University College London and the Engineering and Physical Sciences Research Council (EP/M014649/1).

\section{Disclosures}

There are no conflicts to declare.

\section{References}

[1] George Q. Daley, The Promise and Perils of Stem Cell Therapeutics, Cell Stem Cell 10 (2012) 740-749.

[2] M.A. Fischbach, J.A. Bluestone, W.A. Lim, Cell-Based Therapeutics: The Next Pillar of Medicine, Sci. Transl. Med. 5 (2013) 179ps7.

[3] D.J. Woodsworth, R.A. Holt, Cell-Based Therapeutics: Making a Faustian Pact with Biology, Trends Mol. Med. 23 (2017) 104-115.

[4] H.J. Jackson, S. Rafiq, R.J. Brentjens, Driving CAR T-cells forward, Nat. Rev. Clin. Oncol. 13 (2016) 370.

[5] M. Sadelain, I. Rivière, S. Riddell, Therapeutic T cell engineering, Nature 545 (2017) 423.

[6] U.S. Food and Drug Administration, Approved Cellular and Gene Therapy Products, 2018, https://www.fda.gov/BiologicsBloodVaccines/CellularGeneTherapyProducts/Approved Products/default.htm.

[7] I.M. Barbash, P. Chouraqui, J. Baron, M. Feinberg, S. Etzion, A. Tessone, L. Miller, E. Guetta, D. Zipori, L. Kedes, R. Kloner, Systemic Delivery of Bone Marrow-Derived Mesenchymal Stem Cells to the Infarcted Myocardium, Circulation 108 (2003) 863-868. [8] S. Dimmeler, S. Ding, T.A. Rando, A. Trounson, Translational strategies and challenges in regenerative medicine, Nat. Med. 20 (2014) 814-821.

[9] E. Hill, T. Boontheekul, D.J. Mooney, Regulating activation of transplanted cells controls tissue regeneration, Proc. Natl. Acad. Sci. U. S. A. 103 (2006) 2494-2499.

[10] K. Ban, H.-J. Park, S. Kim, A. Andukuri, K.-W. Cho, J.W. Hwang, H.J. Cha, S.Y. Kim, W.-S. Kim, H.-W. Jun, Y.-S. Yoon, Cell Therapy with Embryonic Stem Cell-Derived Cardiomyocytes Encapsulated in Injectable Nanomatrix Gel Enhances Cell Engraftment and Promotes Cardiac Repair, ACS Nano 8 (2014) 10815-10825.

[11] A.A. Tomei, V. Manzoli, C.A. Fraker, J. Giraldo, D. Velluto, M. Najjar, A. Pileggi, R.D. Molano, C. Ricordi, C.L. Stabler, J.A. Hubbell, Device design and materials optimization of conformal coating for islets of Langerhans, Proc. Natl. Acad. Sci. U.S.A. 111 (2014) 10514. [12] P. Gobbo, A.J. Patil, M. Li, R. Harniman, W.H. Briscoe, S. Mann, Programmed assembly of synthetic protocells into thermoresponsive prototissues, Nat. Mater. 17 (2018) 1145-1153. 
[13] M.B. Gorbet, M.V. Sefton, Biomaterial-associated thrombosis: roles of coagulation factors, complement, platelets and leukocytes, Biomaterials 25 (2004) 5681-5703.

[14] B. Nilsson, O. Korsgren, J.D. Lambris, K.N. Ekdahl, Can cells and biomaterials in therapeutic medicine be shielded from innate immune recognition?, Trends Immunol. 31 (2010) 32-38.

[15] R.M. Hernández, G. Orive, A. Murua, J.L. Pedraz, Microcapsules and microcarriers for in situ cell delivery, Adv. Drug Del. Rev. 62 (2010) 711-730.

[16] D.O. Hebb, The Organization of Behavior, John Wiley \& Sons, New York, 1949.

[17] J.D. Humphrey, E.R. Dufresne, M.A. Schwartz, Mechanotransduction and extracellular matrix homeostasis, Nat. Rev. Mol. Cell Biol. 15 (2014) 802-812.

[18] S.J. Singer, G.L. Nicolson, The Fluid Mosaic Model of the Structure of Cell Membranes, Science 175 (1972) 720-731.

[19] Ü. Coskun, K. Simons, Cell Membranes: The Lipid Perspective, Structure 19 (2011) 1543 1548.

[20] M.D. Mager, V. LaPointe, M.M. Stevens, Exploring and exploiting chemistry at the cell surface, Nat. Chem. 3 (2011) 582-589.

[21] B.M. Gumbiner, Cell Adhesion: The Molecular Basis of Tissue Architecture and Morphogenesis, Cell 84 (1996) 345-357.

[22] H.T. McMahon, J.L. Gallop, Membrane curvature and mechanisms of dynamic cell membrane remodelling, Nature 438 (2005) 590-596.

[23] L.K. Mahal, C.R. Bertozzi, Engineered cell surfaces: fertile ground for molecular landscaping, Chem. Biol. 4 (1997) 415-422.

[24] J.A. Prescher, C.R. Bertozzi, Chemistry in living systems, Nat. Chem. Biol. 1 (2005) 1321.

[25] W. Zhao, G.S.L. Teo, N. Kumar, J.M. Karp, Chemistry and material science at the cell surface, Mater. Today 13 (2010) 14-21.

[26] A.I. Zamaleeva, R.T. Minullina, J.R. Tully, M.R. Dzamukova, S.A. Konnova, E.A. Naumenko, Direct Deposition of Nanomaterials onto Cells, Cell Surface Engineering: Fabrication of Functional Nanoshells, The Royal Society of Chemistry, London, 2014, pp. 2847.

[27] I. Cobo, M. Li, B.S. Sumerlin, S. Perrier, Smart hybrid materials by conjugation of responsive polymers to biomacromolecules, Nat. Mater. 14 (2015) 143-159.

[28] S. Ding, C.P. O'Banion, J.G. Welfare, D.S. Lawrence, Cellular Cyborgs: On the Precipice of a Drug Delivery Revolution, Cell Chem. Biol. 25 (2018) 648-658.

[29] A.E. Nel, L. Madler, D. Velegol, T. Xia, E.M.V. Hoek, P. Somasundaran, F. Klaessig, V. Castranova, M. Thompson, Understanding biophysicochemical interactions at the nano-bio interface, Nat. Mater. 8 (2009) 543-557.

[30] M.T. Stephan, D.J. Irvine, Enhancing cell therapies from the outside in: Cell surface engineering using synthetic nanomaterials, Nano Today 6 (2011) 309-325.

[31] I. Drachuk, M.K. Gupta, V.V. Tsukruk, Biomimetic Coatings to Control Cellular Function through Cell Surface Engineering, Adv. Funct. Mater. 23 (2013) 4437-4453.

[32] D. Xie, C.A. Smyth, C. Eckstein, G. Bilbao, J. Mays, D.E. Eckhoff, J.L. Contreras,

Cytoprotection of PEG-modified adult porcine pancreatic islets for improved

xenotransplantation, Biomaterials 26 (2005) 403-412.

[33] H.R. Rengifo, J.A. Giraldo, I. Labrada, C.L. Stabler, Long-Term Survival of Allograft

Murine Islets Coated via Covalently Stabilized Polymers, Adv. Healthcare Mater. 3 (2014)

1061-1070.

[34] G.W. Cline, S.B. Hanna, The aminolysis of N-hydroxysuccinimide esters. A structurereactivity study, J. Am. Chem. Soc. 109 (1987) 3087-3091.

[35] J.T. Wilson, C.A. Haller, Z. Qu, W. Cui, M.K. Urlam, E.L. Chaikof, Biomolecular surface engineering of pancreatic islets with thrombomodulin, Acta Biomater. 6 (2010) 1895-1903.

[36] Y. Teramura, Y. Kaneda, T. Totani, H. Iwata, Behavior of synthetic polymers immobilized on a cell membrane, Biomaterials 29 (2008) 1345-1355. 
[37] D. Sarkar, P.K. Vemula, G.S.L. Teo, D. Spelke, R. Karnik, L.Y. Wee, J.M. Karp, Chemical Engineering of Mesenchymal Stem Cells to Induce a Cell Rolling Response, Bioconj. Chem. 19 (2008) 2105-2109.

[38] W. Zhao, S. Schafer, J. Choi, Y.J. Yamanaka, M.L. Lombardi, S. Bose, A.L. Carlson, J.A. Phillips, W. Teo, I.A. Droujinine, C.H. Cui, R.K. Jain, J. Lammerding, J.C. Love, C.P. Lin, D.

Sarkar, R. Karnik, J.M. Karp, Cell-surface sensors for real-time probing of cellular environments, Nat. Nanotechnol. 6 (2011) 524-531.

[39] M.T. Stephan, J.J. Moon, S.H. Um, A. Bershteyn, D.J. Irvine, Therapeutic cell engineering with surface-conjugated synthetic nanoparticles, Nat. Med. 16 (2010) 1035-1041.

[40] S.C. Hsiao, B.J. Shum, H. Onoe, E.S. Douglas, Z.J. Gartner, R.A. Mathies, C.R. Bertozzi, M.B. Francis, Direct Cell Surface Modification with DNA for the Capture of Primary Cells and the Investigation of Myotube Formation on Defined Patterns, Langmuir 25 (2009) 6985-6991.

[41] X. Xue, G. Pasparakis, N. Halliday, K. Winzer, S.M. Howdle, C.J. Cramphorn, N.R. Cameron, P.M. Gardner, B.G. Davis, F. Fernández-Trillo, C. Alexander, Synthetic Polymers for Simultaneous Bacterial Sequestration and Quorum Sense Interference, Angew. Chem. Int. Ed. 50 (2011) 9852-9856.

[42] J. Wang, W. Wu, Y. Zhang, X. Wang, H. Qian, B. Liu, X. Jiang, The combined effects of size and surface chemistry on the accumulation of boronic acid-rich protein nanoparticles in tumors, Biomaterials 35 (2014) 866-878.

[43] A. Stephenson-Brown, S. Yong, M.H. Mansor, Z. Hussein, N.-C. Yip, P.M. Mendes, J.S. Fossey, F.J. Rawson, Electronic communication of cells with a surface mediated by boronic acid saccharide interactions, Chem. Commun. 51 (2015) 17213-17216.

[44] J. Kim, Y.M. Lee, H. Kim, D. Park, J. Kim, W.J. Kim, Phenylboronic acid-sugar grafted polymer architecture as a dual stimuli-responsive gene carrier for targeted anti-angiogenic tumor therapy, Biomaterials 75 (2016) 102-111.

[45] N.D. Winblade, I.D. Nikolic, A.S. Hoffman, J.A. Hubbell, Blocking Adhesion to Cell and Tissue Surfaces by the Chemisorption of a Poly-l-lysine-graft-(poly(ethylene glycol);

phenylboronic acid) Copolymer, Biomacromolecules 1 (2000) 523-533.

[46] H. Liu, Y. Li, K. Sun, J. Fan, P. Zhang, J. Meng, S. Wang, L. Jiang, Dual-Responsive Surfaces Modified with Phenylboronic Acid-Containing Polymer Brush To Reversibly Capture and Release Cancer Cells, J. Am. Chem. Soc. 135 (2013) 7603-7609.

[47] D.M. Patterson, L.A. Nazarova, J.A. Prescher, Finding the Right (Bioorthogonal) Chemistry, ACS Chem. Biol. 9 (2014) 592-605.

[48] P. Shi, E. Ju, Z. Yan, N. Gao, J. Wang, J. Hou, Y. Zhang, J. Ren, X. Qu, Spatiotemporal control of cell-cell reversible interactions using molecular engineering, Nat. Commun. 7 (2016) 13088.

[49] Y. Teramura, H. Iwata, Islet encapsulation with living cells for improvement of biocompatibility, Biomaterials 30 (2009) 2270-2275.

[50] J.H. Jeong, J.J. Schmidt, R.E. Kohman, A.T. Zill, R.J. DeVolder, C.E. Smith, M.-H. Lai, A. Shkumatov, T.W. Jensen, L.G. Schook, S.C. Zimmerman, H. Kong, Leukocyte-Mimicking Stem Cell Delivery via in Situ Coating of Cells with a Bioactive Hyperbranched Polyglycerol, J. Am. Chem. Soc. 135 (2013) 8770-8773.

[51] Y. Teramura, S. Asif, K.N. Ekdahl, E. Gustafson, B. Nilsson, Cell Adhesion Induced Using Surface Modification with Cell-Penetrating Peptide-Conjugated Poly(ethylene glycol)-Lipid: A New Cell Glue for 3D Cell-Based Structures, ACS Appl. Mater. Interfaces 9 (2017) 244-254. [52] D. Sarkar, P.K. Vemula, W. Zhao, A. Gupta, R. Karnik, J.M. Karp, Engineered mesenchymal stem cells with self-assembled vesicles for systemic cell targeting, Biomaterials 31 (2010) 5266-5274.

[53] A. Pulsipher, M.E. Griffin, S.E. Stone, J.M. Brown, L.C. Hsieh-Wilson, Directing Neuronal Signaling through Cell-Surface Glycan Engineering, J. Am. Chem. Soc. 136 (2014) 6794-6797.

[54] P. Rajagopalan, C.J. Shen, F. Berthiaume, A.W. Tilles, M. Toner, M.L. Yarmush, Polyelectrolyte Nano-scaffolds for the Design of Layered Cellular Architectures, Tissue Eng. 12 (2006) 1553-1563. 
[55] W. Li, T. Guan, X. Zhang, Z. Wang, M. Wang, W. Zhong, H. Feng, M. Xing, J. Kong, The Effect of Layer-by-Layer Assembly Coating on the Proliferation and Differentiation of Neural Stem Cells, ACS Appl. Mater. Interfaces 7 (2015) 3018-3029.

[56] J.T. Wilson, W. Cui, V. Kozlovskaya, E. Kharlampieva, D. Pan, Z. Qu, V.R.

Krishnamurthy, J. Mets, V. Kumar, J. Wen, Y. Song, V.V. Tsukruk, E.L. Chaikof, Cell Surface Engineering with Polyelectrolyte Multilayer Thin Films, J. Am. Chem. Soc. 133 (2011) 70547064.

[57] J. de Kruif, M. Tijmensen, J. Goldsein, T. Logtenberg, Recombinant lipid-tagged antibody fragments as functional cell-surface receptors, Nat. Med. 6 (2000) 223.

[58] X. Chen, X. Zhang, H.-Y. Wang, Z. Chen, F.-G. Wu, Subcellular Fate of a Fluorescent Cholesterol-Poly(ethylene glycol) Conjugate: An Excellent Plasma Membrane Imaging Reagent, Langmuir 32 (2016) 10126-10135.

[59] C.J. Capicciotti, C. Zong, M.O. Sheikh, T. Sun, L. Wells, G.-J. Boons, Cell-Surface GlycoEngineering by Exogenous Enzymatic Transfer Using a Bifunctional CMP-Neu5Ac Derivative, J. Am. Chem. Soc. 139 (2017) 13342-13348.

[60] M. Ayer, H.-A. Klok, Cell-mediated delivery of synthetic nano- and microparticles, J. Controlled Release 259 (2017) 92-104.

[61] C.M. Csizmar, J.R. Petersburg, A. Hendricks, L.A. Stern, B.J. Hackel, C.R. Wagner, Engineering Reversible Cell-Cell Interactions with Lipid Anchored Prosthetic Receptors, Bioconj. Chem. 29 (2018) 1291-1301.

[62] R.J. Weber, S.I. Liang, N.S. Selden, T.A. Desai, Z.J. Gartner, Efficient Targeting of FattyAcid Modified Oligonucleotides to Live Cell Membranes through Stepwise Assembly, Biomacromolecules 15 (2014) 4621-4626.

[63] E.C. Woods, N.A. Yee, J. Shen, C.R. Bertozzi, Glycocalyx Engineering with a Recycling Glycopolymer that Increases Cell Survival In Vivo, Angew. Chem. Int. Ed. 54 (2015) 1578215788.

[64] C.M. Hui, J. Pietrasik, M. Schmitt, C. Mahoney, J. Choi, M.R. Bockstaller, K. Matyjaszewski, Surface-Initiated Polymerization as an Enabling Tool for Multifunctional (Nano-)Engineered Hybrid Materials, Chem. Mater. 26 (2014) 745-762.

[65] J.Y. Kim, B.S. Lee, J. Choi, B.J. Kim, J.Y. Choi, S.M. Kang, S.H. Yang, I.S. Choi, Cytocompatible Polymer Grafting from Individual Living Cells by Atom-Transfer Radical Polymerization, Angew. Chem. Int. Ed. 55 (2016) 15306-15309.

[66] J. Niu, D.J. Lunn, A. Pusuluri, J.I. Yoo, M.A. O'Malley, S. Mitragotri, H.T. Soh, C.J. Hawker, Engineering live cell surfaces with functional polymers via cytocompatible controlled radical polymerization, Nat. Chem. 9 (2017) 537.

[67] M. Mammen, S.-K. Choi, G.M. Whitesides, Polyvalent Interactions in Biological Systems: Implications for Design and Use of Multivalent Ligands and Inhibitors, Angew. Chem. Int. Ed. 37 (1998) 2754-2794.

[68] L.G. Griffith, M.A. Swartz, Capturing complex 3D tissue physiology in vitro, Nat. Rev. Mol. Cell Biol. 7 (2006) 211-224.

[69] F. Pampaloni, E.G. Reynaud, E.H.K. Stelzer, The third dimension bridges the gap between cell culture and live tissue, Nat. Rev. Mol. Cell Biol. 8 (2007) 839-845.

[70] K.A. Fitzgerald, M. Malhotra, C.M. Curtin, F.J. O' Brien, C.M. O' Driscoll, Life in 3D is never flat: 3D models to optimise drug delivery, J. Controlled Release 215 (2015) 39-54.

[71] M. Heiss, M. Hellström, M. Kalén, T. May, H. Weber, M. Hecker, H.G. Augustin, T.

Korff, Endothelial cell spheroids as a versatile tool to study angiogenesis in vitro, FASEB J. 29 (2015) 3076-3084.

[72] C.Y. Tay, M.S. Muthu, S.L. Chia, K.T. Nguyen, S.-S. Feng, D.T. Leong, Reality Check for Nanomaterial-Mediated Therapy with 3D Biomimetic Culture Systems, Adv. Funct. Mater. 26 (2016) 4046-4065.

[73] S.B. Shah, A. Singh, Cellular self-assembly and biomaterials-based organoid models of development and diseases, Acta Biomater. 53 (2017) 29-45.

[74] H.-F. Lu, K.-N. Chua, P.-C. Zhang, W.-S. Lim, S. Ramakrishna, K.W. Leong, H.-Q. Mao, Three-dimensional co-culture of rat hepatocyte spheroids and NIH/3T3 fibroblasts enhances hepatocyte functional maintenance, Acta Biomater. 1 (2005) 399-410. 
[75] M.A. Schwartz, C.S. Chen, Deconstructing Dimensionality, Science 339 (2013) 402-404.

[76] M.G. Rubashkin, G. Ou, V.M. Weaver, Deconstructing Signaling in Three Dimensions, Biochemistry 53 (2014) 2078-2090.

[77] B. Jiang, L. Yan, Z. Miao, E. Li, K.H. Wong, R.-H. Xu, Spheroidal formation preserves human stem cells for prolonged time under ambient conditions for facile storage and transportation, Biomaterials 133 (2017) 275-286.

[78] E. Fennema, N. Rivron, J. Rouwkema, C. van Blitterswijk, J. de Boer, Spheroid culture as a tool for creating 3D complex tissues, Trends Biotechnol. 31 (2013) 108-115.

[79] D. Duguay, R.A. Foty, M.S. Steinberg, Cadherin-mediated cell adhesion and tissue segregation: qualitative and quantitative determinants, Dev. Biol. 253 (2003) 309-323.

[80] F. Hirschhaeuser, H. Menne, C. Dittfeld, J. West, W. Mueller-Klieser, L.A. KunzSchughart, Multicellular tumor spheroids: An underestimated tool is catching up again, J. Biotechnol. 148 (2010) 3-15.

[81] M.W. Laschke, M.D. Menger, Life is 3D: Boosting Spheroid Function for Tissue Engineering, Trends Biotechnol. 35 (2017) 133-144.

[82] J. Fukuda, Y. Sakai, K. Nakazawa, Novel hepatocyte culture system developed using microfabrication and collagen/polyethylene glycol microcontact printing, Biomaterials 27 (2006) 1061-1070.

[83] J. Lee, M.J. Cuddihy, G.M. Cater, N.A. Kotov, Engineering liver tissue spheroids with inverted colloidal crystal scaffolds, Biomaterials 30 (2009) 4687-4694.

[84] G. Su, Y. Zhao, J. Wei, J. Han, L. Chen, Z. Xiao, B. Chen, J. Dai, The effect of forced growth of cells into 3D spheres using low attachment surfaces on the acquisition of stemness properties, Biomaterials 34 (2013) 3215-3222.

[85] C.G. Anene-Nzelu, K.Y. Peh, A. Fraiszudeen, Y.H. Kuan, S.H. Ng, Y.C. Toh, H.L. Leo, H. $\mathrm{Yu}$, Scalable alignment of three-dimensional cellular constructs in a microfluidic chip, Lab Chip 13 (2013) 4124-4133.

[86] K. Hu, N. Zhou, Y. Li, S. Ma, Z. Guo, M. Cao, Q. Zhang, J. Sun, T. Zhang, N. Gu, Sliced Magnetic Polyacrylamide Hydrogel with Cell-Adhesive Microarray Interface: A Novel Multicellular Spheroid Culturing Platform, ACS Appl. Mater. Interfaces 8 (2016) 15113-15119. [87] M. Zanoni, F. Piccinini, C. Arienti, A. Zamagni, S. Santi, R. Polico, A. Bevilacqua, A. Tesei, 3D tumor spheroid models for in vitro therapeutic screening: a systematic approach to enhance the biological relevance of data obtained, Sci. Rep. 6 (2016) 19103.

[88] J. Candiello, T.S.P. Grandhi, S.K. Goh, V. Vaidya, M. Lemmon-Kishi, K.R. Eliato, R. Ros, P.N. Kumta, K. Rege, I. Banerjee, 3D heterogeneous islet organoid generation from human embryonic stem cells using a novel engineered hydrogel platform, Biomaterials 177 (2018) 2739.

[89] C.-C. Lin, A. Raza, H. Shih, PEG hydrogels formed by thiol-ene photo-click chemistry and their effect on the formation and recovery of insulin-secreting cell spheroids, Biomaterials 32 (2011) 9685-9695.

[90] L.D. Amer, A. Holtzinger, G. Keller, M.J. Mahoney, S.J. Bryant, Enzymatically degradable poly(ethylene glycol) hydrogels for the 3D culture and release of human embryonic stem cell derived pancreatic precursor cell aggregates, Acta Biomater. 22 (2015) 103-110. [91] Y. Wu, Z. Zhao, Y. Guan, Y. Zhang, Galactosylated reversible hydrogels as scaffold for HepG2 spheroid generation, Acta Biomater. 10 (2014) 1965-1974.

[92] S. Halldorsson, E. Lucumi, R. Gómez-Sjöberg, R.M.T. Fleming, Advantages and challenges of microfluidic cell culture in polydimethylsiloxane devices, Biosensors Bioelectron. 63 (2015) 218-231.

[93] X. Cui, Y. Hartanto, H. Zhang, Advances in multicellular spheroids formation, J. R. Soc., Interface 14 (2017).

[94] S.H. Bhang, S.-W. Cho, W.-G. La, T.-J. Lee, H.S. Yang, A.-Y. Sun, S.-H. Baek, J.-W. Rhie, B.-S. Kim, Angiogenesis in ischemic tissue produced by spheroid grafting of human adipose-derived stromal cells, Biomaterials 32 (2011) 2734-2747.

[95] M.W. Laschke, T.E. Schank, C. Scheuer, S. Kleer, S. Schuler, W. Metzger, D. Eglin, M. Alini, M.D. Menger, Three-dimensional spheroids of adipose-derived mesenchymal stem cells 
are potent initiators of blood vessel formation in porous polyurethane scaffolds, Acta Biomater. 9 (2013) 6876-6884.

[96] T. Takebe, K. Sekine, M. Enomura, H. Koike, M. Kimura, T. Ogaeri, R.-R. Zhang, Y. Ueno, Y.-W. Zheng, N. Koike, S. Aoyama, Y. Adachi, H. Taniguchi, Vascularized and functional human liver from an iPSC-derived organ bud transplant, Nature 499 (2013) 481-484. [97] H. Koo, M. Choi, E. Kim, S.K. Hahn, R. Weissleder, S.H. Yun, Bioorthogonal Click Chemistry-Based Synthetic Cell Glue, Small 11 (2015) 6458-6466.

[98] C.-C. Huang, H.-J. Wei, K.-J. Lin, W.-W. Lin, C.-W. Wang, W.-Y. Pan, S.-M. Hwang, Y. Chang, H.-W. Sung, Multimodality noninvasive imaging for assessing therapeutic effects of exogenously transplanted cell aggregates capable of angiogenesis on acute myocardial infarction, Biomaterials 73 (2015) 12-22.

[99] T. Takebe, M. Enomura, E. Yoshizawa, M. Kimura, H. Koike, Y. Ueno, T. Matsuzaki, T. Yamazaki, T. Toyohara, K. Osafune, H. Nakauchi, Hiroshi Y. Yoshikawa, H. Taniguchi, Vascularized and Complex Organ Buds from Diverse Tissues via Mesenchymal Cell-Driven Condensation, Cell Stem Cell 16 (2015) 556-565.

[100] Y.S. Park, J.-Y. Hwang, Y. Jun, Y.M. Jin, G. Kim, H.Y. Kim, H.S. Kim, S.-H. Lee, I. Jo, Scaffold-free parathyroid tissue engineering using tonsil-derived mesenchymal stem cells, Acta Biomater. 35 (2016) 215-227.

[101] C.S. Ong, X. Zhou, J. Han, C.Y. Huang, A. Nashed, S. Khatri, G. Mattson, T. Fukunishi, H. Zhang, N. Hibino, In vivo therapeutic applications of cell spheroids, Biotechnol. Adv. 36 (2018) 494-505.

[102] Y. Fukuda, T. Akagi, T. Asaoka, H. Eguchi, K. Sasaki, Y. Iwagami, D. Yamada, T. Noda, K. Kawamoto, K. Gotoh, S. Kobayashi, M. Mori, Y. Doki, M. Akashi, Layer-by-layer cell coating technique using extracellular matrix facilitates rapid fabrication and function of pancreatic $\beta$-cell spheroids, Biomaterials 160 (2018) 82-91.

[103] D.E. Brooks, The effect of neutral polymers on the electrokinetic potential of cells and other charged particles: II. A model for the effect of adsorbed polymer on the diffuse double layer, J. Colloid Interface Sci. 43 (1973) 687-699.

[104] S. Chien, K.-m. Jan, Ultrastructural basis of the mechanism of rouleaux formation, Microvasc. Res. 5 (1973) 155-166.

[105] S. Chien, L. Sung, Physicochemical basis and clinical implications of red cell aggregation, Clin. Hemorheol. Microcirc. 7 (1987) 71-91.

[106] B. Neu, H.J. Meiselman, Depletion-Mediated Red Blood Cell Aggregation in Polymer Solutions, Biophys. J. 83 (2002) 2482-2490.

[107] P.J. O'Brien, W. Luo, D. Rogozhnikov, J. Chen, M.N. Yousaf, Spheroid and Tissue Assembly via Click Chemistry in Microfluidic Flow, Bioconj. Chem. 26 (2015) 1939-1949.

[108] D. Rogozhnikov, P.J. O'Brien, S. Elahipanah, M.N. Yousaf Scaffold Free Bio-orthogonal Assembly of 3-Dimensional Cardiac Tissue via Cell Surface Engineering, Sci. Rep. 6 (2016) 39806.

[109] D. Dutta, A. Pulsipher, W. Luo, M.N. Yousaf, Synthetic Chemoselective Rewiring of Cell Surfaces: Generation of Three-Dimensional Tissue Structures, J. Am. Chem. Soc. 133 (2011) 8704-8713.

[110] W. Luo, A. Pulsipher, D. Dutta, B.M. Lamb, M.N. Yousaf, Remote Control of Tissue Interactions via Engineered Photo-switchable Cell Surfaces, Sci. Rep. 4 (2014) 6313.

[111] W. Luo, N. Westcott, D. Dutta, A. Pulsipher, D. Rogozhnikov, J. Chen, M.N. Yousaf, A Dual Receptor and Reporter for Multi-Modal Cell Surface Engineering, ACS Chem. Biol. 10 (2015) 2219-2226.

[112] E. Saxon, C.R. Bertozzi, Cell Surface Engineering by a Modified Staudinger Reaction, Science 287 (2000) 2007-2010.

[113] R.A. Chandra, E.S. Douglas, R.A. Mathies, C.R. Bertozzi, M.B. Francis, Programmable Cell Adhesion Encoded by DNA Hybridization, Angew. Chem. Int. Ed. 45 (2006) 896-901.

[114] Z.J. Gartner, C.R. Bertozzi, Programmed assembly of 3-dimensional microtissues with defined cellular connectivity, Proc. Natl. Acad. Sci. U.S.A. 106 (2009) 4606-4610. 
[115] M.E. Todhunter, N.Y. Jee, A.J. Hughes, M.C. Coyle, A. Cerchiari, J. Farlow, J.C. Garbe, M.A. LaBarge, T.A. Desai, Z.J. Gartner, Programmed synthesis of three-dimensional tissues, Nat. Methods 12 (2015) 975.

[116] E. Akbari, Y. Mollica Molly, R. Lucas Christopher, M. Bushman Sarah, A. Patton Randy, M. Shahhosseini, W. Song Jonathan, E. Castro Carlos, Engineering Cell Surface Function with DNA Origami, Adv. Mater. 29 (2017) 1703632.

[117] H. Koo, S.K. Hahn, S.H. Yun, Controlled Detachment of Chemically Glued Cells, Bioconj. Chem. 27 (2016) 2601-2604.

[118] Y. Iwasaki, M. Sakiyama, S. Fujii, S.-i. Yusa, Surface modification of mammalian cells with stimuli-responsive polymers, Chem. Commun. 49 (2013) 7824-7826.

[119] A.J.R. Amaral, G. Pasparakis, Macromolecular cell surface engineering for accelerated and reversible cellular aggregation, Chem. Commun. 51 (2015) 17556-17559.

[120] A.J.R. Amaral, G. Pasparakis, Rapid Formation of Cell Aggregates and Spheroids Induced by a "Smart" Boronic Acid Copolymer, ACS Appl. Mater. Interfaces 8 (2016) 2293022941.

[121] G. Pasparakis, A. Cockayne, C. Alexander, Control of Bacterial Aggregation by Thermoresponsive Glycopolymers, J. Am. Chem. Soc. 129 (2007) 11014-11015.

[122] J. Quirós, A.J.R. Amaral, G. Pasparakis, G.R. Williams, R. Rosal, Electrospun boronic acid-containing polymer membranes as fluorescent sensors for bacteria detection, React. Funct. Polym. 121 (2017) 23-31.

[123] A.Y. Koyfman, G.B. Braun, N.O. Reich, Cell-Targeted Self-Assembled DNA Nanostructures, J. Am. Chem. Soc. 131 (2009) 14237-14239.

[124] K.K. Ahmed, S.M. Geary, A.K. Salem, Chapter 7 - Engineering the Surface of Cells Using Biotin-Avidin Chemistry, Micro- and Nanoengineering of the Cell Surface, William Andrew Publishing, Oxford, 2014, pp. 143-155.

[125] B. Wang, J. Song, H. Yuan, C. Nie, F. Lv, L. Liu, S. Wang, Multicellular Assembly and Light-Regulation of Cell-Cell Communication by Conjugated Polymer Materials, Adv. Mater. 26 (2013) 2371-2375.

[126] W. Dai, J. Belt, W.M. Saltzman, Cell-binding Peptides Conjugated to Poly(ethylene glycol) Promote Neural Cell Aggregation, Nat. Biotechnol. 12 (1994) 797-801.

[127] W. Dai, W.M. Saltzman, Fibroblast aggregation by suspension with conjugates of poly(ethylene glycol) and RGD, Biotechnol. Bioeng. 50 (1996) 349-356.

[128] W. Meier, Reversible Cell Aggregation Induced by Specific Ligand-Receptor Coupling, Langmuir 16 (2000) 1457-1459.

[129] P. Gong, W. Zheng, Z. Huang, W. Zhang, D. Xiao, X. Jiang, A Strategy for the Construction of Controlled, Three-Dimensional, Multilayered, Tissue-Like Structures, Adv. Funct. Mater. 23 (2013) 42-46.

[130] P.A. De Bank, B. Kellam, D.A. Kendall, K.M. Shakesheff, Surface engineering of living myoblasts via selective periodate oxidation, Biotechnol. Bioeng. 81 (2003) 800-808.

[131] P.A. De Bank, Q. Hou, R.M. Warner, I.V. Wood, B.E. Ali, S. MacNeil, D.A. Kendall, B. Kellam, K.M. Shakesheff, L.D.K. Buttery, Accelerated formation of multicellular 3-D structures by cell-to-cell cross-linking, Biotechnol. Bioeng. 97 (2007) 1617-1625.

[132] G.R. Kirkham, E. Britchford, T. Upton, J. Ware, G.M. Gibson, Y. Devaud, M. Ehrbar, M. Padgett, S. Allen, L.D. Buttery, K. Shakesheff, Precision Assembly of Complex Cellular Microenvironments using Holographic Optical Tweezers, Sci. Rep. 5 (2015) 8577.

[133] V. Gribova, R. Auzely-Velty, C. Picart, Polyelectrolyte Multilayer Assemblies on Materials Surfaces: From Cell Adhesion to Tissue Engineering, Chem. Mater. 24 (2012) 854869.

[134] A.J. Swiston, J.B. Gilbert, D.J. Irvine, R.E. Cohen, M.F. Rubner, Freely Suspended Cellular "Backpacks" Lead to Cell Aggregate Self-Assembly, Biomacromolecules 11 (2010) 1826-1832.

[135] M. Matsusaki, K. Kadowaki, Y. Nakahara, M. Akashi, Fabrication of Cellular Multilayers with Nanometer-Sized Extracellular Matrix Films, Angew. Chem. Int. Ed. 46 (2007) 46894692 . 
[136] Y. Amano, A. Nishiguchi, M. Matsusaki, H. Iseoka, S. Miyagawa, Y. Sawa, M. Seo, T. Yamaguchi, M. Akashi, Development of vascularized iPSC derived 3D-cardiomyocyte tissues by filtration Layer-by-Layer technique and their application for pharmaceutical assays, Acta Biomater. 33 (2016) 110-121.

[137] K. Sasaki, T. Akagi, T. Asaoka, H. Eguchi, Y. Fukuda, Y. Iwagami, D. Yamada, T. Noda, H. Wada, K. Gotoh, K. Kawamoto, Y. Doki, M. Mori, M. Akashi, Construction of threedimensional vascularized functional human liver tissue using a layer-by-layer cell coating technique, Biomaterials 133 (2017) 263-274.

[138] S. Krol, M. Nolte, A. Diaspro, D. Mazza, R. Magrassi, A. Gliozzi, A. Fery, Encapsulated Living Cells on Microstructured Surfaces, Langmuir 21 (2005) 705-709.

[139] R.F. Fakhrullin, M.-L. Brandy, O.J. Cayre, O.D. Velev, V.N. Paunov, Live celloidosome structures based on the assembly of individual cells by colloid interactions, Phys. Chem. Chem. Phys. 12 (2010) 11912-11922.

[140] M.-L. Brandy, O.J. Cayre, R.F. Fakhrullin, O.D. Velev, V.N. Paunov, Directed assembly of yeast cells into living yeastosomes by microbubble templating, Soft Matter 6 (2010) 34943498.

[141] A. Ciupa, P.A. De Bank, L. Caggiano, Multicellular aggregation of maltol-modified cells triggered by Fe3+ ions, Chem. Commun. 49 (2013) 10148-10150.

[142] S.-M. Ong, L. He, N.T. Thuy Linh, Y.-H. Tee, T. Arooz, G. Tang, C.-H. Tan, H. Yu, Transient inter-cellular polymeric linker, Biomaterials 28 (2007) 3656-3667.

[143] D. Zhao, S.-M. Ong, Z. Yue, Z. Jiang, Y.-C. Toh, M. Khan, J. Shi, C.-H. Tan, J.P. Chen, $\mathrm{H}$. Yu, Dendrimer hydrazides as multivalent transient inter-cellular linkers, Biomaterials 29 (2008) 3693-3702.

[144] X. Mo, Q. Li, L.W. Yi Lui, B. Zheng, C.H. Kang, B. Nugraha, Z. Yue, R.R. Jia, H.X. Fu, D. Choudhury, T. Arooz, J. Yan, C.T. Lim, S. Shen, C. Hong Tan, H. Yu, Rapid construction of mechanically- confined multi- cellular structures using dendrimeric intercellular linker,

Biomaterials 31 (2010) 7455-7467.

[145] M. Ito, T. Taguchi, Enhanced insulin secretion of physically crosslinked pancreatic $\beta$-cells by using a poly(ethylene glycol) derivative with oleyl groups, Acta Biomater. 5 (2009) 29452952.

[146] T. Taguchi, Z. Rao, M. Ito, M. Matsuda, Induced albumin secretion from HepG2 spheroids prepared using poly(ethylene glycol) derivative with oleyl groups, J. Mater. Sci. Mater. Med. 22 (2011) 2357.

[147] Z. Rao, M. Sasaki, T. Taguchi, Development of amphiphilic, enzymatically-degradable PEG-peptide conjugate as cell crosslinker for spheroid formation, Colloids Surf. B.

Biointerfaces 101 (2013) 223-227.

[148] J.-Y. Shin, J. Park, H.-K. Jang, T.-J. Lee, W.-G. La, S.H. Bhang, I.K. Kwon, O.H. Kwon, B.-S. Kim, Efficient formation of cell spheroids using polymer nanofibers, Biotechnol. Lett. 34 (2012) 795-803.

[149] E. Kim, J.C. Kim, K. Min, M. Goh, G. Tae, Rapid and Versatile Cell Aggregate Formation Using Lipid-Conjugated Heparin, ACS Appl. Mater. Interfaces 10 (2018) 2443124439.

[150] G.R. Souza, J.R. Molina, R.M. Raphael, M.G. Ozawa, D.J. Stark, C.S. Levin, L.F. Bronk, J.S. Ananta, J. Mandelin, M.-M. Georgescu, J.A. Bankson, J.G. Gelovani, T.C. Killian, W.

Arap, R. Pasqualini, Three-dimensional tissue culture based on magnetic cell levitation, Nat. Nanotechnol. 5 (2010) 291.

[151] S. Ghosh, S.R.P. Kumar, I.K. Puri, S. Elankumaran, Magnetic assembly of 3D cell clusters: visualizing the formation of an engineered tissue, Cell Prolif. 49 (2016) 134-144. [152] G. Frasca, V. Du, J.C. Bacri, F. Gazeau, C. Gay, C. Wilhelm, Magnetically shaped cell aggregates: from granular to contractile materials, Soft Matter 10 (2014) 5045-5054.

[153] G. Frasca, F. Gazeau, C. Wilhelm, Formation of a Three-Dimensional Multicellular Assembly Using Magnetic Patterning, Langmuir 25 (2009) 2348-2354.

[154] M.D. Krebs, R.M. Erb, B.B. Yellen, B. Samanta, A. Bajaj, V.M. Rotello, E. Alsberg, Formation of Ordered Cellular Structures in Suspension via Label-Free Negative Magnetophoresis, Nano Lett. 9 (2009) 1812-1817. 
[155] D. Fayol, G. Frasca, C. Le Visage, F. Gazeau, N. Luciani, C. Wilhelm, Use of Magnetic Forces to Promote Stem Cell Aggregation During Differentiation, and Cartilage Tissue Modeling, Adv. Mater. 25 (2013) 2611-2616.

[156] S. Gupta, R.G. Alargova, P.K. Kilpatrick, O.D. Velev, On-Chip Dielectrophoretic Coassembly of Live Cells and Particles into Responsive Biomaterials, Langmuir 26 (2010) 3441-3452.

[157] Y. Krishnamachari, M.E. Pearce, A.K. Salem, Self-Assembly of Cell-Microparticle Hybrids, Adv. Mater. 20 (2008) 989-993.

[158] K.Y. Lee, H.J. Kong, R.G. Larson, D.J. Mooney, Hydrogel Formation via Cell Crosslinking, Adv. Mater. 15 (2003) 1828-1832.

[159] W. Meier, J. Hotz, S. Günther-Ausborn, Vesicle and Cell Networks: Interconnecting Cells by Synthetic Polymers, Langmuir 12 (1996) 5028-5032.

[160] V. Javvaji, M.B. Dowling, H. Oh, I.M. White, S.R. Raghavan, Reversible gelation of cells using self-assembling hydrophobically-modified biopolymers: towards self-assembly of tissue, Biomaterials Science 2 (2014) 1016-1023.

[161] A.J.R. Amaral, M. Emamzadeh, G. Pasparakis, Transiently malleable multi-healable hydrogel nanocomposites based on responsive boronic acid copolymers, Polym. Chem. 9 (2018) 525-537.

[162] V. Mironov, R.P. Visconti, V. Kasyanov, G. Forgacs, C.J. Drake, R.R. Markwald, Organ printing: Tissue spheroids as building blocks, Biomaterials 30 (2009) 2164-2174.

[163] I.T. Ozbolat, Bioprinting scale-up tissue and organ constructs for transplantation, Trends Biotechnol. 33 (2015) 395-400.

[164] I. Donderwinkel, J.C.M. van Hest, N.R. Cameron, Bio-inks for 3D bioprinting: recent advances and future prospects, Polym. Chem. 8 (2017) 4451-4471.

[165] W. Peng, D. Unutmaz, I.T. Ozbolat, Bioprinting towards Physiologically Relevant Tissue Models for Pharmaceutics, Trends Biotechnol. 34 (2016) 722-732.

[166] H. Jian, M. Wang, S. Wang, A. Wang, S. Bai, 3D bioprinting for cell culture and tissue fabrication, Bio-Design and Manufacturing 1 (2018) 45-61.

[167] S. Vijayavenkataraman, W.-C. Yan, W.F. Lu, C.-H. Wang, J.Y.H. Fuh, 3D bioprinting of tissues and organs for regenerative medicine, Adv. Drug Del. Rev. 132 (2018) 296-332.

[168] K. Jakab, A. Neagu, V. Mironov, R.R. Markwald, G. Forgacs, Engineering biological structures of prescribed shape using self-assembling multicellular systems, Proc. Natl. Acad. Sci. U. S. A. 101 (2004) 2864.

[169] M.O. Christopher, M. Francoise, F. Gabor, M.H. Cheryl, Biofabrication and testing of a fully cellular nerve graft, Biofabrication 5 (2013) 045007.

[170] C. Kucukgul, S.B. Ozler, I. Inci, E. Karakas, S. Irmak, D. Gozuacik, A. Taralp, B. Koc, 3D bioprinting of biomimetic aortic vascular constructs with self-supporting cells, Biotechnol. Bioeng. 112 (2014) 811-821.

[171] S.B. Nupura, M. Vijayan, M. Solange, T. Ali, G. Masoumeh, M. Mario, L. Qi, Z. Yu Shrike, S. Su Ryon, C. Giovanni, A. Nasim, D.S. Thomas, E.B. Colin, A. Anthony, R.D.

Mehmet, K. Ali, A liver-on-a-chip platform with bioprinted hepatic spheroids, Biofabrication 8 (2016) 014101.

[172] C. Norotte, F.S. Marga, L.E. Niklason, G. Forgacs, Scaffold-free vascular tissue engineering using bioprinting, Biomaterials 30 (2009) 5910-5917.

[173] M. Itoh, K. Nakayama, R. Noguchi, K. Kamohara, K. Furukawa, K. Uchihashi, S. Toda, J.-i. Oyama, K. Node, S. Morita, Scaffold-Free Tubular Tissues Created by a Bio-3D Printer Undergo Remodeling and Endothelialization when Implanted in Rat Aortae, PLoS One 10 (2015) e0136681.

[174] C.S. Ong, T. Fukunishi, H. Zhang, C.Y. Huang, A. Nashed, A. Blazeski, D. DiSilvestre, L. Vricella, J. Conte, L. Tung, G.F. Tomaselli, N. Hibino, Biomaterial-Free Three-Dimensional Bioprinting of Cardiac Tissue using Human Induced Pluripotent Stem Cell Derived Cardiomyocytes, Sci. Rep. 7 (2017) 4566.

[175] A.B. Elena, V.K. Elizaveta, D. Jonathan, H. Charlotte, D.A.S.P. Frederico, A.P. Vladislav, S. Yi, W. Qi, A.A. Suraya, K.S. Irina, S.S. Natalia, A.F. Georgy, D.K. Yusef, E.P. 
Christophe, A.M. Vladimir, Bioprinting of a functional vascularized mouse thyroid gland construct, Biofabrication 9 (2017) 034105.

[176] A. Adil, Y. Yin, T.O. Ibrahim, Microfabrication of scaffold-free tissue strands for threedimensional tissue engineering, Biofabrication 7 (2015) 031002.

[177] Y. Yu, K.K. Moncal, J. Li, W. Peng, I. Rivero, J.A. Martin, I.T. Ozbolat, Three-

dimensional bioprinting using self-assembling scalable scaffold-free "tissue strands" as a new bioink, Sci. Rep. 6 (2016) 28714.

[178] M. Hospodiuk, M. Dey, D. Sosnoski, I.T. Ozbolat, The bioink: A comprehensive review on bioprintable materials, Biotechnol. Adv. 35 (2017) 217-239.

[179] S. Sugimoto, R. Moriyama, T. Mori, Y. Iwasaki, Surface engineering of macrophages with nucleic acid aptamers for the capture of circulating tumor cells, Chem. Commun. 51 (2015) 17428-17430.

[180] L.-H. Liu, W.-X. Qiu, Y.-H. Zhang, B. Li, C. Zhang, F. Gao, L. Zhang, X.-Z. Zhang, A Charge Reversible Self-Delivery Chimeric Peptide with Cell Membrane-Targeting Properties for Enhanced Photodynamic Therapy, Adv. Funct. Mater. 27 (2017) 1700220.

[181] H.-R. Jia, Y.-X. Zhu, K.-F. Xu, X. Liu, F.-G. Wu, Plasma membrane-anchorable photosensitizing nanomicelles for lipid raft-responsive and light-controllable intracellular drug delivery, J. Controlled Release 286 (2018) 103-113.

[182] A.-N. Zhang, W. Wu, C. Zhang, Q.-Y. Wang, Z.-N. Zhuang, H. Cheng, X.-Z. Zhang, A versatile bacterial membrane-binding chimeric peptide with enhanced photodynamic antimicrobial activity, J. Mater. Chem. B 7 (2019) 1087-1095.

[183] R. Rajan, F. Hayashi, T. Nagashima, K. Matsumura, Toward a Molecular Understanding of the Mechanism of Cryopreservation by Polyampholytes: Cell Membrane Interactions and Hydrophobicity, Biomacromolecules 17 (2016) 1882-1893.

[184] M. Nagao, J. Sengupta, D. Diaz-Dussan, M. Adam, M. Wu, J. Acker, R. Ben, K. Ishihara, H. Zeng, Y. Miura, R. Narain, Synthesis of Highly Biocompatible and Temperature-Responsive Physical Gels for Cryopreservation and 3D Cell Culture, ACS Applied Bio Materials 1 (2018) 356-366.

[185] G. Huang, F. Li, X. Zhao, Y. Ma, Y. Li, M. Lin, G. Jin, T.J. Lu, G.M. Genin, F. Xu, Functional and Biomimetic Materials for Engineering of the Three-Dimensional Cell Microenvironment, Chem. Rev. 117 (2017) 12764-12850.

[186] H.W. Ooi, S. Hafeez, C.A. van Blitterswijk, L. Moroni, M.B. Baker, Hydrogels that listen to cells: a review of cell-responsive strategies in biomaterial design for tissue regeneration, Mater. Horiz. 4 (2017) 1020-1040. 